NBER WORKING PAPER SERIES

THE ECONOMICS OF HURRICANES IN THE UNITED STATES

William D. Nordhaus

Working Paper 12813

http://www.nber.org/papers/w12813

\author{
NATIONAL BUREAU OF ECONOMIC RESEARCH \\ 1050 Massachusetts Avenue \\ Cambridge, MA 02138 \\ December 2006
}

This is a revised version of papers prepared for the Annual Meetings of the American Economic Association, Boston, Massachusetts, January, 2006; the Snowmass Workshop on Abrupt and Catastrophic Climate Change, Snowmass, Colorado, July-August, 2006; the Yale Workshop on Environmental Economics; and a Cowles Foundation Seminar. The author is grateful for research assistance and mapping help from David Corderi, Kyle Hood, and Justin Lo, for comments from participants in the meetings, and for comments on an earlier draft by William Cline and Roger Pielke, Jr. The views expressed herein are those of the author(s) and do not necessarily reflect the views of the National Bureau of Economic Research.

(C) 2006 by William D. Nordhaus. All rights reserved. Short sections of text, not to exceed two paragraphs, may be quoted without explicit permission provided that full credit, including $\odot$ notice, is given to the source. 
The Economics of Hurricanes in the United States

William D. Nordhaus

NBER Working Paper No. 12813

December 2006

JEL No. Q0,Q5,Q54

\begin{abstract}
$\underline{\text { ABSTRACT }}$
The year 2005 brought record numbers of hurricanes and storm damages to the United States. Was this a foretaste of increasingly destructive hurricanes in an era of global warming? This study examines the economic impacts of U.S. hurricanes. The major conclusions are the following: First, there appears to be an increase in the frequency and intensity of tropical cyclones in the North Atlantic. Second, there are substantial vulnerabilities to intense hurricanes in the Atlantic coastal United States. Damages appear to rise with the eighth power of maximum wind speed. Third, greenhouse warming is likely to lead to stronger hurricanes, but the evidence on hurricane frequency is unclear. We estimate that the average annual U.S. hurricane damages will increase by $\$ 8$ billion at 2005 incomes ( 0.06 percent of GDP) due to global warming. However, this number may be underestimated by current storm models. Fourth, 2005 appears to have been a quadruple outlier, involving a record number of North Atlantic tropical cyclones, a large fraction of intense storms, a large fraction of the intense storms making landfall in the United States, and an intense storm hitting the most vulnerable high-value region in the country.

William D. Nordhaus

Yale University, Department of Economics

28 Hillhouse Avenue

Box 208264

New Haven, CT 06520-8264

and NBER

william.nordhaus@yale.edu
\end{abstract}


North Atlantic hurricanes in 2005 broke many records: most hurricanes (fifteen), most major hurricanes hitting the United States (four), the strongest recorded hurricane, and the most category 5 hurricanes (four). On the economic front, Hurricane Katrina was (in inflation corrected prices) the costliest hurricane in U.S. history. ${ }^{2}$

Was 2005 a harbinger of a new era of increasingly destructive hurricanes? Does it reflect global warming? What kinds of policies should be undertaken to cope with rising seas and the possibility of more intense hurricanes? Should cities like New Orleans be abandoned to return to salt marshes or ocean? There can be no definitive answers to these questions, but this study provides an analysis of the economic issues involved.

\section{Geophysical background}

\section{A. What are hurricanes?}

Hurricanes are the name given to the North Atlantic versions of a spectacular natural phenomenon known as "tropical cyclones." Such storms are known as "tropical storms" when they reach maximum sustained surface winds of at least 17 meters per second (mps) - or, equivalently, 34 nautical miles per hour (kts) or 39 miles per hour (mph). If sustained winds reach $33 \mathrm{mps}$ (64 kts or $74 \mathrm{mph}$ ), they are called "hurricanes" in the North Atlantic Ocean.

Tropical cyclones (TCs) are giant heat engines fueled by condensation of warm water, with a positive feedback loop whereby stronger winds lead to lower pressure, increased evaporation and condensation, and yet stronger winds. The genesis of hurricanes is incompletely understood, but one important necessary condition is sea-surface water temperature of at least $26.5^{\circ} \mathrm{C}\left(80^{\circ} \mathrm{F}\right)$. Moreover, there are thermodynamic upper limits on the strength of hurricanes, determined primarily by ocean temperature.

\footnotetext{
2 Details on the estimation are available in a document, William D. Nordhaus, "Notes on Data and Methods: The Economics of Hurricanes in the United States," December 21, 2006, at http:// www.econ.yale.edu/ nordhaus/homepage/recent_stuff.html. This will be referred to as Accompanying Notes.
} 


\section{B. Are there trends in the frequency or intensity of tropical cyclones?}

On a global scale, the annual number of TCs over the 1970-2004 period averaged around 85. ${ }^{3}$ It is unclear whether there are long-term trends or cycles in global TC frequency, which is not surprising given that reliable data are only available since the advent of satellite data in 1960.4 Since this paper involves primarily the United States, we focus on TCs in the North Atlantic. Using "best track" or HURDAT data for North Atlantic storms, there is a clear increase in the frequency of storms over the 1851-2005 period, particularly since 1980.5 The increase in hurricane frequency is positively and significantly related to seasurface temperatures in the cyclogenic North Atlantic (SST).

Recent studies indicate that there has been an increase in the intensity of storms in the North Atlantic over the last three decades. Hurricane "power" is conventionally defined as a function of maximum wind speed squared or cubed. NOAA has constructed a power index called ACE ("accumulated cyclone energy") index, which is a function of maximum wind speed squared. ${ }^{6}$ Emanuel defines a "power dissipation index" (PDI) as a function of the cube of maximum wind speed summed each six hours over the life of the cyclone. His calculations indicate that PDI has increased markedly since the mid-1970s. ${ }^{7}$ Figure 1 shows

\footnotetext{
3 P. J. Webster, G. J. Holland, J. A. Curry, H.-R. Chang, "Changes in Tropical Cyclone Number, Duration, and Intensity in a Warming Environment," Science, 16 September 2005, Vol. 309. no. 5742, pp. 1844 - 1846.
}

4 Some of the difficulties of measuring long-term trends are described in Christopher W. Landsea, Bruce A. Harper, Karl Hoarau, and John A. Knaff, "Can We Detect Trends in Extreme Tropical Cyclones?" Science, 28 July 2006, vol. 313. no. 5786, pp. 452 - 454.

${ }^{5}$ According to the U.S. National Oceanic and Atmospheric Administration, "HURDAT is the official record of tropical storms and hurricanes for the Atlantic Ocean, Gulf of Mexico and Caribbean Sea, including those that have made landfall in the United States." (http://www.aoml.noaa.gov/hrd/hurdat/)

6 "The ACE index is calculated by summing the squares of the 6-hourly maximum sustained wind speed for all named storms during their existence as a tropical storm or hurricane." (Gerald D. Bell, Michael S. Halpert, Russell C. Schnell, R. Wayne Higgins, Jay Lawrimore, Vernon E. Kousky, Richard Tinker, Wasila Thiaw, Muthuvel Chelliah, and Anthony Artusa, "Climate Assessment for 1999," Bulletin of the American Meteorological Society, Vol. 81, No. 6, June 2000, pp. S1-S50.)

7 Kerry Emanuel, "Increasing destructiveness of tropical cyclones over the past 30 years," Nature, 436, 4 August 2005, pp. 686 - 688. 
Emanuel's unsmoothed PDI and tropical North Atlantic SST over the 1949-2005 period. A statistical analysis indicates that the semi-elasticity of PDI per TC with respect to SST is $0.73( \pm 0.23) .8$

Climatologists have constructed a complete history of North Atlantic tropical storms back to 1851 . These data are inherently less accurate because of missing ocean data in early years. Figure 2 shows a long-term power index constructed in a manner similar to that in Figure 1. A time-series analysis of the long-term power index in Figure 2 and SST finds that changes in hurricane power are significantly related to SST changes.

These results indicate that there appears to be an increase in the intensity and frequency of tropical storms in the North Atlantic in the last quarter-century. Both increases appear to be primarily associated with sea-surface warming in the tropical North Atlantic.

\section{Was 2005 an unusual year for the United States?}

2005 was an outlier in terms of hurricane power. Emanuel's estimates rank 2005 as the stormiest year over his 57-year record. My longer term estimate put 2005 as the second stormiest over the 155-year record. However, 2005 was an outlier primarily because the number of storms was high as opposed to the average power per storm being high.

\section{How vulnerable are different regions?}

The vulnerability of the economy to hurricanes will depend in part on the frequency and intensity of storms. The other major factor is the location of economic activity. How vulnerable are different regions? We can get a rough estimate of the "intrinsic vulnerability" by examining the magnitude of the nation's capital stock that is in coastal areas and at low elevation. For this purpose, I have applied the "G-Econ data set" to estimate disaggregated regional economic vulnerability. This data set provides comprehensive global estimates of gross

${ }^{8}$ Note for non-economists: Elasticities are commonly used to show the scale-free proportional relationships between variables. In this context, the elasticity of $y$ with respect to $\mathrm{x}$ is the percentage change in $\mathrm{y}$ for each percentage change in $\mathrm{x}$. Analytically, this is calculated as $\partial[\ln (\mathrm{y})] / \partial[\ln (\mathrm{x})]$. The semi-elasticity, which is convenient for the economic estimates below, is equal to $\partial[\ln (y)] / \partial x$. 
domestic product, average elevation, distance from coastline, and population for $1^{\circ}$ latitude $\times 1^{\circ}$ longitude. ${ }^{9}$ For the present study, I further divided the country into subgridcells of $10^{\prime}$ by $10^{\prime}$ (approximately 15 by 15 kilometers) for the vulnerable Atlantic coast of the United States, and then estimated the capital stocks for each subgridcell.

Figure 3 gives a picture of the vulnerable areas of the coastal Atlantic. For this figure, we select all coastal subgridcells with elevation less than 8 meters and with 2005 capital stocks of more than $\$ 1$ billion. These areas are vulnerable to the large storm surges that might accompany intense hurricanes. The major concentrations of vulnerable economic activity and capital (with capital stock greater than $\$ 100$ billion) are the Miami coast, New Orleans, Houston, and Tampa.

\section{Economic Impacts of Hurricanes}

\section{A. Background}

The economic impacts of hurricanes during a year depend upon several factors: total output, the capital-intensity of output, the location of economic activity, the number of storms, the intensity of storms, and the geographical features of the affected areas.

The analysis initially considers only three factors: the number of storms, maximum wind speed at landfall, and GDP. In subsequent sections and the Appendix, we consider more complete measures of storm characteristics. The impact of the number of storms is obvious, and we take damages to be linear in frequency. For the initial analysis, we normalize the current-dollar damages in a year by that year's nominal GDP. This normalization is an appropriate correction for economic growth and inflation assuming no adaptation and neutral changes in technology and the location and structure of economic activity. However, several factors might lead the damage function to shift over time. These "drift factors" over time include population migration, rising housing values, sea-level rise, measurement errors, building codes, and adaptation to storms. An examination of various drift factors suggests that the damage-GDP ratio may have risen in the

\footnotetext{
9 The methodology and data as well as selected relationships are contained in William Nordhaus, "Geography and Macroeconomics: New Data and New Findings," Proceedings of the National Academy of Sciences (US), March 7, 2006, vol. 103, no. 10, pp. 3510-3517. The complete data set is on the web at www.gecon.yale.edu .
} 
order of $1^{1 / 2}$ percent per year over the last half-century. ${ }^{10}$ However, many of these trends are likely to abate, and we project no further drift in the future.

The third factor affecting damage is wind speed. It has been conventional in the past to assume that damages are a function of wind speed to either the second or third power. ${ }^{11}$ However, as we see below, this presumption is based on an energy-wind speed relationship, which is not necessarily applicable to the impact of wind and water on designed structures. Hence, we treat the exponent on wind speed as a behavioral parameter to be estimated.

10 There has been no significant change in the national nominal capital-nominal GDP ratio in recent decades (based on BEA data). However, the nominal market value of household real estate has risen 0.20 percent per year faster than nominal GDP over the 1952-2006 period (based on Federal Reserve Flow of Funds data). Moreover, there has been rapid population migration to coastal communities, which raises vulnerability. Approximately half of hurricane power over land has intersected Florida, and Florida's share of GDP or personal income has risen on average around 2 percent annually over the last half century (based on BEA and Census data). An additional factor affecting estimates over time is the convention of estimating total damages as a multiple of (two times) insured damages, which might bias estimates if coverage ratios or deductibles have changed. There has been some upward trend in the ratio of casualty premiums to the total capital stock, but data on hurricane insurance coverage is not readily available. Our discussion below suggests that sea-level rise might account for a rise of $1 / 4$ percent per year in vulnerable capital. Totaling these factors would yield an upward trend in the damage-GDP relationship of around 1 1/2 percent per year. For a detailed discussion of drift factors, see Accompanying Notes.

11 Some examples are the following: (1) The widely used ACE index described above assumes that storm intensity is measured by the square of wind speed. (2) "[T]he amount of damage increases roughly as the square of the intensity of the storms, as measured by their maximum wind speed ..." (Kerry Emanuel, "Anthropogenic Effects on Tropical Cyclone Activity," at http://wind.mit.edu/ emanuel/anthro.html, undated.) (3) "But the amount of damage increases roughly as the cube of the maximum wind speed in storms..." (Kerry Emanuel, "Increasing destructiveness of tropical cyclones over the past 30 years," Nature, 436, 4 August 2005, pp. 686-688). (4) "Because damage increases with at least the square of wind speed..." (Roger A. Pielke, Jr. and Christopher W. Landsea, "La Niña, El Niño, and Atlantic Hurricane Damages in the United States," Bull. Amer. Meteor. Soc., 2002, vol. 80, 2027-2033). 


\section{B. The damage-intensity function and initial empirical estimates}

We next investigate the relationship between normalized damages and maximum wind speed, which we call the damage-intensity function. We have gathered data on the storm characteristics and economic damages for 142 hurricanes that have made landfall in the United States. These include all storms since 1933 and 14 storms before 1933.12 Figure 4 shows the trend in normalized hurricane damages since 1950. 2005 stands out from the crowd. 2005 was an economic outlier primarily because Hurricane Katrina ( $\$ 81$ billion) was by a wide margin the most costly hurricane in recent history. Katrina was so costly not because of its intensity but because it hit the most economically vulnerable region in the United States, as we saw in Figure 3.

Figure 5 shows a scatter plot of wind speed and normalized damages for the hurricanes with complete data since 1950. Using the entire sample, we estimate a double-log relationship between normalized damage and maximum wind speed, including time to control for drift factors. The basic damage-intensity function is:

$$
\ln \left(\text { cost }_{i t} / G D P_{t}\right)=\alpha+\beta \ln \left(\text { maxwind }_{i t}\right)+\delta \text { year }_{t}+\varepsilon_{i t} .
$$

In equation (1), cost $t_{i t}$ is estimated total damages for hurricane $i$ in year $t$ in current prices, maxwind ${ }_{i t}$ is estimated maximum sustained wind speed at landfall, $G D P_{t}$ is U.S. gross domestic product in current prices, year ${ }_{i t}$ is the year, and $\varepsilon_{i t}$ is a residual error. Greek letters are estimated coefficients. We first show the ordinary least squares (OLS) estimate of equation (1) for the entire sample:

$$
\ln \left(\operatorname{cost}_{i t} / G D P_{t}\right)=\alpha+\underset{[8.5]}{7.3} \ln \left(\text { maxwind }_{i t}\right)+\underset{[4.1]}{0.029} \text { year }_{t}+\varepsilon_{i t}
$$

The numbers in brackets are the t-statistics on the coefficients. This regression contains one of the major surprises of this paper. The regression indicates that the elasticity of damages with respect to maximum wind speed is extremely high,

${ }^{12}$ The major early study in this area is R. A. Pielke, Jr. and C. W. Landsea, "Normalized Hurricane Damages in the United States: 1925-1995," Weather and Forecasting, 1998, vol.

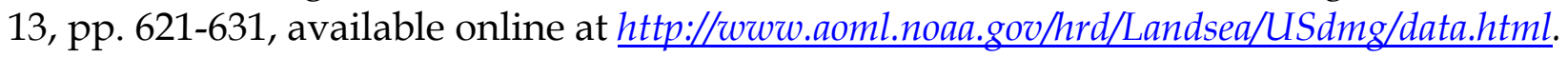
We have verified their data, added data for recent years, and corrected a few small errors. For a discussion of data, see the Accompanying Notes. 
with the OLS estimate of 7.3. This is at first blush a substantial puzzle. This elasticity is vastly larger than the standard presumption just cited of an elasticity of 2 or 3 . In the subsequent sections, we investigate the reasons for the super-high elasticity. In the end, we conclude that the estimate in $\left(1^{\prime}\right)$ is actually an underestimate of the parameter, and we estimate that an exponent of 8 on maximum wind speed is the best estimate. We denote this relationship as the eighth-power law of damages.

\section{Why the super-high elasticity of damages?}

What are the reasons for the super-high elasticity in the eighth-power law? There are three possible reasons. These concern (1) potential biases because of the omitted storm variables, (2) statistical bias, and (3) the engineering relationship between stress and damage. We discuss each of these in turn.

\section{Storm size, duration, and alternative measures of capital vulnerability}

The estimates of the damage function in equation (1) use a readily available measure of storm intensity, the maximum sustained wind speed at landfall in the United States. These estimates do not account for other characteristics of the storm or of the affected geography and economy. In principle, we would want to include some measure of the vulnerable capital in the storm's path, the lifetime of the storm, its size, as well as other geographical features. The Appendix describes extensions of the simplest storm characteristic both to determine how much is missed in the simple index and to determine whether the eighth-power law of damages can be explained by omitted variables such as other storm characteristics. I will summarize those results here.

We can extend the variable used in equation (1) - maximum sustained wind at landfall - to include three other important factors: the entire time series of central wind speeds (which are available in the "best track" data set), the wind speeds for the entire region affected by the storm, and the quantity of vulnerable capital affected by the storm.

The Appendix describes four alternative and more comprehensive indexes of storm characteristics: The "capital vulnerability index," or CVI $(N)$, which is calculated for different exponents on wind speed, $N$; the "terrestrial power dispersion index," or TPDI(N), calculated for different powers of wind speed; the "unweighted capital vulnerability index to $100 \mathrm{~km}$," or UCVI-100; and the "unweighted capital vulnerability index to $200 \mathrm{~km}$," or UCVI-200. In very 
summary form, these indexes include the entire storm track over the U.S. mainland, account for wind speed along the track and not just at landfall, and (except for TPDI) include estimates from the G-Econ database of the capital stock in the path of the storm.

We can summarize the results from the Appendix as follows: Using an OLS specification for hurricanes since 1950, we find that, for the simplest specification in equation (1) above, hurricane damages rise as the 7.2 power of maximum wind speed at landfall.

The four augmented measures of storm characteristics have higher likelihood than the simplest estimate in equation $\left(1^{\prime}\right)$, indicating that accounting for vulnerable capital and the entire storm path improves the fit. The maximumlikelihood specification is the unweighted capital vulnerability index to $200 \mathrm{~km}$, or UCVI-200. Using this specification, the exponent on wind speed is around $81 / 2$ [see specifications (f) in Table A1]. The other measures have estimated maximumlikelihood estimates of the parameters between 4.4 and over 11 . The finding of a super-high elasticity of damages with respect to wind speed is found in all alternative specifications, although in some cases the statistical significance is low.

\section{Statistical bias}

The second question involves the statistical reliability of the estimates. The main statistical concerns with the super-high damage elasticity are errors in measurement of wind speed and correlation of wind speed with omitted variables [as represented by $\varepsilon_{i t}$ in equation (1)].

The simplest procedure is to account for possible errors in measurement in maximum wind speed. We have estimated equation (1) using four different approaches, and the results are shown in Table 1. The first two rows are ordinary least squares estimates for all 142 hurricanes and for the 45 hurricanes since 1980. We focus on the period since 1980 because the wind-speed data are more reliable for the later period. ${ }^{13}$ The second two rows use two-stage least squares (TSLS) estimation. TSLS estimation is useful if we suspect that the estimates are

13 The historical hurricane database includes revalidated maximum wind speed only since 1980. 
contaminated by errors in measurement of maximum wind speed. ${ }^{14}$ For the TSLS estimates, we use as instruments variables (IV) minimum pressure and the value of the Saffir-Simpson scale, which are generally assumed to have less measurement error than estimated maximum wind speed.

The full-sample ordinary least squares (OLS) estimator has the lowest elasticity estimate of 7.3. The estimated OLS coefficient for the post-1980 period is 8.5. The TSLS estimates yield a higher elasticity than the OLS - as would be expected if the wind speed is measured with substantial error - with 9.1 for the longer period and 9.7 for the shorter period.

In addition, the Appendix presents TSLS estimates where we use our four augmented measures of storm intensity described in the last section. For three of the four augmented measures, the TSLS estimate of the wind speed exponent is between 8.0 and 8.2. For the fourth, the TSLS estimate is slightly above 10 .

\section{Damages in designed structures}

The finding of the super-high elasticity appears to survive the use of augmented measures of storm intensity as well as estimates that examine statistical bias. In this section, we suggest that the reason for the super-high elasticity is that physical damages are highly non-linear functions of wind and water stress in the relevant regions. The empirical functions will differ for different materials (brittle v. flexible), for different objects (houses v. crops), and for different design tolerances (see Figure 6 for current U.S. coastal wind standards for building design).

One example of the relationship is the classical strain-stress-fracture relationships used in mechanical engineering and building design. For many materials, catastrophic failure occurs when the stress exceeds a given level. If we were to estimate the elasticity of damages with respect to a stress (such as wind or water), it would be very small up to the fracture level and then extremely high as the material fractured. Figure 7 shows a stress-strain curve for a brittle material. Little or no damage occurs for low stress, but for high stress the material bends. Catastrophic fracture occurs at point 5.

\footnotetext{
${ }^{14}$ A discussion of the role of TSLS and IV estimators can be found in surveys of econometrics, for example Jeffrey M. Wooldridge, Introductory Econometrics: A Modern Approach, Third Edition, Cincinnati, OH, South-Western, 2006.
} 
Going from engineering to actual damages involves aggregation over different structures, materials, building codes, age of structures, and other factors. The threshold effects were illustrated by the rupture of the levees of New Orleans. The role of catastrophic non-linear damages was even more dramatically shown by the collapse of the World Trade Towers on September 11, 2001. In both cases, it is possible that a slightly smaller stress would have led to far smaller damages. If structures are designed to withstand stresses up to the 50-year storm and have severe damage when one occurs, then intense hurricanes (which are lowprobability events) will cause large damages where they hit, and the winddamage elasticity is likely to be much higher than the physics power curve in the vicinity of the fracture point.

\section{Summary}

Given the number and complexity of relationships entering the wind speeddamage relationship, it is unlikely that the actual relationship can be derived from first principles. At this point, we make the following tentative conclusions about the reasons for the super-high elasticity of damages with respect to maximum wind speed. First, it seems unlikely that this result comes from measurement errors as it is robust to several different measures and estimation techniques. Second, the economic vulnerability increases very sharply with maximum winds. This arises because of a non-linear relationship between wind speed and damage, because the "cone" of high winds increases sharply with maximum wind speed, and because storm lifetime is positively associated with maximum wind speed. Third, because hurricanes are rare events, we are likely to observe the wind speeddamage relationship at exactly the point where sharply non-linear and therefore catastrophic failures arise. We should not be surprised if the empirical wind speed-damage relationship has a completely different structure from the physical wind-power function.

Taking all these factors together, the weight of the evidence puts the empirical exponent of wind speed between 8 and 9, with a slight preference to the lower end. For the balance of this study, I use an elasticity of damages with respect to maximum wind speed of 8 as a reasonable synthesis - this being the eighth power law of damages. ${ }^{15}$

\footnotetext{
${ }^{15}$ It is a close call whether to conclude that the empirical elasticity is eight or nine. An earlier draft suggested a ninth power law. However, estimates with the capital vulnerability indexes in the Appendix suggest that eight is a better central estimate. Further data are needed to refine the estimates and determine whether they are robust across different regions.
} 


\section{Time trends and the lessening hypothesis}

A standard presumption in the literature on environmental vulnerability is the "lessening hypothesis," whereby societies have become less vulnerable over time to environmental shocks. Examples of declining sensitivity include the impacts of draughts on agriculture or nutrition and the impacts of weather extremes on human health. ${ }^{16}$

Our estimates indicate that the time trend in the damage function is positive. For example, the time trend in the OLS full-sample equation found that normalized damages have risen by $2.9( \pm 0.76)$ percent per year, indicating increased vulnerability to storms of a given size. ${ }^{17}$ The coefficient is slightly higher than the presumption, discussed above, that related damages to coastal population, housing values, and sea-level rise. The Appendix examines the time coefficient in equations with the augmented storm intensity variables. Those estimates are robustly in the range between $2^{1 / 2}$ and $3 \frac{1}{2}$ percent per year. The finding of a "worsening" trend has troubling implications for damages in a warmer world, but we are unable to refine the estimate with current data.

\section{Global warming and Hurricanes: Some Inconvenient Truths}

Hurricanes have been a major scientific and economic concern partly because 2005 was so unusual and partly because of fears that global warming might bring a string of hurricanes like Katrina. Are terrible and costly events such

\footnotetext{
${ }^{16}$ Warrick, R. A. “Drought In The Great Plains: A Case Study Of Research On Climate And Society In The USA," in Climatic Constraints and Human Activities, eds. Ausubel, J. and Biswas, A. K., Pergamon, Oxford, 1980, pp. 93-123; Jesse H. Ausubel, “Does Climate Still Matter?" Nature, vol. 350, 25 April 1991, pp. 649-652. In economic affairs, there has been a trend toward substantially lower variability in output growth (the "Great Moderation") in the last half century.
}

17 This is contrary to Roger A. Pielke, Jr., "Are There Trends in Hurricane Destruction?" Nature, Vol. 438, December 2005, E11, who reports no statistically significant trend. Similar negative results were found in Roger A. Pielke, Jr. and Christopher W. Landsea, "La Niña, El Niño, and Atlantic Hurricane Damages in the United States," Bull. Amer. Meteor. Soc., vol. 80, 2027-2033. Additionally, issues of comparability over time are nontrivial, as is discussed in Christopher W. Landsea, "Hurricanes and Global Warming," Nature, Vol. 438, December 2005, E11-E12. The reasons for the difference in findings have not been resolved. 
as Katrina and the inundation of New Orleans likely to recur frequently in the future? The answer is probably not, but much here is murky. In this section, we estimate the impact on hurricane damages of an equilibrium doubling of atmospheric $\mathrm{CO}_{2}$ concentrations. For reference purposes, current economic and climate projections would place our $\mathrm{CO}_{2}$ scenario around the year 2100 .

\section{A. Functional forms for economics and global warming}

The relationship between hurricane damages and global warming is a complex function of economics, geography, and geophysics. We have described some of the contributing variables in the section on capital vulnerability above. In this section, I assume that maximum wind speed at landfall is a sufficient statistic for storm characteristics. Therefore, central estimates below consider only the number of hurricanes, the size of the economy, and the impact of warming on hurricane intensity as measured by maximum wind speed. For estimation purposes, I use the following functional form for damage per hurricane:

$$
\ln \left(V_{i t} / Q_{t}\right)=\alpha+\beta \ln \left[\left(1+\gamma \Delta S S T_{t}\right) w_{i n d}\right]+\varepsilon_{i t}
$$

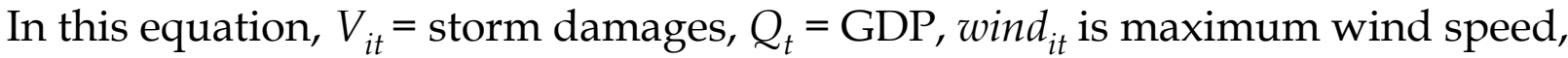
and $\Delta S S T_{t}=$ change in sea-surface temperature in the cyclogenic region. The diverse unmeasured locational and storm factors as well as stochastic factors are collected in $\varepsilon_{i t}$. We will also assume that $S S T_{t}$ is a function of $T_{t}=$ global mean surface temperature. The effect of global warming will enter through the expression, $\beta \ln \left[\left(1+\gamma \Delta S S T_{t}\right)\right.$ wind $\left._{i t}\right]$. This term contains the wind speed-damage elasticity $\beta$ (discussed above) and the impact of increased SST on maximum wind speed given by the coefficient $\gamma$ (discussed in the next section), while $\alpha$ is a scale parameter. We later consider some further refinements.

\section{B. Parameter estimates from geophysics}

The basic physics linking global warming and tropical cyclones is clear if complex. Global warming might affect hurricanes in several dimensions, including the frequency, size, intensity, lifetime, and geographic distribution of tropical cyclones. Of the five, the only clear link from basic geophysics is between global warming and cyclonic intensity. As sea-surface temperature rises, the "potential intensity" or upper limit of cyclonic wind speed increases (holding other factors constant). 
Early calculations by Emanuel indicated that each degree $C$ of warming of sea-surface temperature (SST) would lead to an increase in potential intensity (maximum wind speed) of 5.5 percent. That is, the semi-elasticity of maximum wind speed with respect to SST, denoted in equation (2) as $\gamma$, is estimated to be 0.055.18 Using several global circulation models (GCMs), Knutson and Tuleya estimated the distribution of hurricane intensity with the current (pre-globalwarming) climate and with a climate of doubled $\mathrm{CO}_{2}$ concentrations. Their study indicated that the maximum wind speed would increase by 5.8 percent in the high- $\mathrm{CO}_{2}$ world with a $1.7^{\circ} \mathrm{C}$ increase in tropical sea-surface temperatures. ${ }^{19}$

These experiments indicate a semi-elasticity of maximum wind speed with respect to SST, $\gamma=0.035$. To move from potential intensity to the actual distribution, statistical work of Emanuel found that there is a uniform distribution of the ratio of actual maximum wind speed to potential maximum wind speed. ${ }^{20}$ If this relationship holds in the warmer world, it would imply that the distribution of actual hurricane intensity would increase with the increase in potential intensity.

Estimating the impact of climate change on hurricanes further requires an estimate of changes to SST in the tropical Atlantic. General circulation models suggest that the equilibrium impact of doubling of atmospheric $\mathrm{CO}_{2}$ concentrations would be an increase in tropical Atlantic SST around $2.5^{\circ} \mathrm{C}$. Using the estimated impact from the Knutson and Tuleya study, global warming would increase maximum wind speed of 8.7 percent. The theoretical presumption and GCM modeling results indicate no increase in cyclonic frequency, and I adopt this assumption for the central case.

18 Kerry A. Emanuel, “The Dependence of Hurricane Intensity on Climate," Nature, 326, April 8, 1987, pp. $483-485$.

${ }^{19}$ A discussion and report on simulations is contained in Thomas R. Knutson and Robert E. Tuleya, "Impact Of CO2-Induced Warming On Simulated Hurricane Intensity And Precipitation: Sensitivity To The Choice Of Climate Model And Convective Parameterization," Journal of Climate, Vol. 17, No. 18, September 15, 2004, p. 3477-95.

${ }^{20}$ K. Emanuel, "A Statistical Analysis of Tropical Cyclone Intensity," Monthly Weather Review, 128, April 2000, pp. 1139-1152. 


\section{Observational evidence}

Recent observational data on the tropical North Atlantic indicate that both the frequency and intensity of hurricanes differ significantly from the modeling conclusions reported in the last section. First, the annual frequency of hurricanes has in fact moved positively with SST. Using the historical data shown in Figure 2, the estimated semi-elasticity of frequency with respect to SST is $0.63( \pm 0.15)$, while the semi-elasticity of average power (maximum wind speed cubed) with respect to SST is $0.73( \pm 0.23) .{ }^{21}$ These semi-elasticities are much larger than the theoretical presumptions of 0.00 and $0.105-0.165$ for frequency and intensity discussed in the last section. ${ }^{22}$

\section{Estimates of mean impacts}

We consider the impact of global warming on both the mean impact and the tails of the distribution of hurricane damages. Estimating the mean impact of global warming is conceptually straightforward under the logarithmic specification in equation (2). The ratio of the mean impact with warming to that without global warming is equal to the product of the elasticity of damages with respect to wind speed $(\beta)$, the semi-elasticity of increased wind speed with respect to mean temperature $(\gamma)$, and the increase in mean temperature $(\Delta S S T)$.

Table 2 shows numerical estimates of the percentage increase in hurricane damages using estimates of the three parameters in equation (2) from this study and from the scientific literature as discussed above. For these estimates, I use an

${ }^{21}$ A standard procedure in much time-series work in this area is to smooth the series before graphical presentation or statistical estimation. That procedure is not appropriate if there is no autoregressive or moving-average (ARMA) structure to the errors. There appears to be no significant ARMA structure for either the hurricane frequency or average hurricane power.

22 The simple bivariate relationships between SST and frequency or intensity are clearly oversimplified. A more complete system would require including variables such as vertical wind shear, low-level vorticity, and an ENSO index (Emanuel, personal communication). When these are included, however, issues of causality arise. If the ultimate driver is either North Atlantic or global SST, then the coefficient estimates described in the text would be the appropriate reduced-form coefficients. For a discussion of estimation of reduced-form methods, see for example Jeffrey $\mathrm{M}$. Wooldridge, Introductory Econometrics: A Modern Approach, Third Edition, Cincinnati, OH, South-Western, 2006. 
elasticity of $\beta=8.5$ and remove the time trend from the damage function. The central estimate is that the impact of an equilibrium doubling of $\mathrm{CO}_{2}$-equivalent atmospheric concentrations would lead to an increase in the mean hurricane damages of 104 percent. Additionally, the table shows five estimates with alternative values of the parameters, with the increase ranging from 29 percent to 2018 percent. The low end would reflect a conventional wind speed-damage elasticity of three. The high end uses the lower end of the empirical estimate of the frequency and intensity elasticities for the period 1949-2005.

To translate these estimates into actual dollars, I assume the appropriate sample is the number, intensity, and damages of hurricanes making landfall in the United States for the 1933-2005 period. Table 3 shows the estimates from Table 2 normalized by the history. We show the results both as a percent of GDP and as scaled to 2005 GDP levels. The mean damages for the period 1933-2005 is 0.062 percent of GDP ( $\$ 7.7$ billion, scaled to 2005 GDP). The impact of global warming is shown in the last column of Table 3. According to the calculations described above, the mean expected impact would be to increase the impacts by 0.064 percent of GDP ( $\$ 8.0$ billion).

\section{E. Frequency distribution of outcomes}

One important characteristic of hurricanes is the skewed distribution of outcomes, which is particularly notable in Figure 4. To examine the extreme outcomes, I estimate the frequency distribution of annual hurricane damages with and without global warming. The parameters are chosen so that the means, variances, and skewness parameters of the simulation match the historical experience. For these estimates, I assume that landfalling hurricane frequency is given by a Poisson distribution with a mean frequency of $1.8=(281 / 155)$ per year. The distribution of storm intensities is given by the historical distribution for landfalling hurricanes. To capture random variation in storm and locational characteristics, I assume that damages have random log-normal errors with a standard deviation of 0.65 . The distribution of maximum wind speeds with global warming is given by shifting the distribution of maximum wind speeds upward by 8.7 percent. Note that this experiment does not include any time trend or adjustment for frequency, adaptation, or sea-level rise. (See Accompanying Notes cited in footnote 2 for a further description of the methodology.)

Table 3 shows the results of the distribution analysis. Because of the superhigh elasticity of damages, the distribution of extremely costly storms is expected to increase sharply. The damages for the $99^{\text {th }}$ percentile of years (that is, the value 
that exceeds 99 percent of years) is calculated to be about 0.7 percent of GDP without warming and 1.4 percent of GDP with global warming.

\section{F. The year 2005 as outlier or early warming of warming?}

We can use the estimated frequency distribution to ask if 2005 was a signal of global warming ... or just a huge outlier. The evidence in Table 3 suggests that 2005 would be a major outlier even in a warmer world. In terms of Emanuel's power index, 2005 was 4.9 times the mean power for the historical period and 3.8 times the estimated mean power for the global warming scenario. In terms of cost, 2005 was 13 times the mean annual hurricane damage for the historical period and 6.5 the estimated mean annual hurricane damage with global warming.

The distributions can also put two major recent hurricanes in perspective. According to the estimates in Table 3, the damages from Hurricane Andrew in 1992 were a 97.7 percentile event without global warming but would be a 93.2 percentile event with global warming. Hurricane Katrina is estimated to be a 98.8 percentile impact event without global warming but would be a 96.5 percentile event with global warming. In other words, we would expect hurricanes with impact as high as Katrina once every 86 years without global warming but once every 28 years with global warming. Therefore, while we can take comfort that we are unlikely to have year after year of Katrina-type experiences, such years of high damages would recur occasionally on a century scale.

\section{Damages with Sea-Level Rise, Adaptation, and Retreat}

Two further complications are the impacts of potential sea-level rise (SLR) accompanying global warming and the potential for adaptation to the threat of more intense hurricanes. The methodology used to estimate the impacts of global warming assumes the historical damage function estimated in equation (1) without the time trend or SLR and assuming that no future steps are taken to reduce vulnerability. We address these issues briefly. 


\section{A. Sea-level rise}

While there has been much research on the economic impacts of SLR,23 relatively little of this research has examined the interaction of SLR with hurricanes. The nub of the issue is the following: As sea level rises, a larger fraction of the capital stock becomes vulnerable to storm surges and water damage. However, depending upon the speed of the SLR, the vulnerability can be reduced if capital migrates to higher and safer locations. The vulnerability to SLR depends primarily on capital mobility, which in turn depends upon the type of capital (compare airplanes with ports), the depreciation rate (compare houses with computers), as well as coordination factors and political boundaries (such as the location of cities, building codes, and national boundaries). Additionally, adaptation will depend upon risk awareness, risk aversion, and the availability and markup on insurance - each of which raises the possibility of seriously distorted decision making.

I have estimated the potential effect of SLR on hurricane damages by examining the fraction of the capital stock that is vulnerable to flooding and storm surges for hurricanes of different intensities. The calculations are as follows. Using the G-Econ data described above, I estimate the distribution of the capital stock as a function of elevation. I then use standard estimates of the relationship between storm surges and elevation, along with estimates of hurricane frequency, to estimate the expected value of capital that is vulnerable to flooding. (See Accompanying Notes for a full description.)

Using this methodology, I estimate that, to a first approximation, the vulnerability of the capital stock to hurricanes doubles with a meter of SLR. Recent central estimates are that sea-level has risen about $2 \frac{1 / 2}{2 m}$ per year in the last two decades and is projected to rise about $5 \mathrm{~mm}$ per year over the next century. ${ }^{24}$ Assuming that damages are proportional to vulnerable capital, this

${ }^{23}$ Gary Yohe, James Neumann, Patrick Marshall, and Holly Ameden, "The Economic Cost Of Greenhouse-Induced Sea-Level Rise For Developed Property In The United States," Climatic Change, Vol. 32, No. 4, April 1996, pp. 387 - 410 and Gary W. Yohe and Michael E. Schlesinger, "Sea-Level Change: The Expected Economic Cost Of Protection Or Abandonment In The United States," Climatic Change, Vol. 38, No. 4, April 1998, pp. $447-472$.

24 The most recent IPCC report estimated a SLR of $0.7 \mathrm{~mm}$ per year for the 1910-1990 period; the report projected SLR of between 9 and $88 \mathrm{~cm}$ for the 1990-2100 period with a central estimate of $48 \mathrm{~cm}$ or $4.4 \mathrm{~mm}$ per year. (Contribution of Working Group I to the Third Assessment Report of the Intergovernmental Panel on Climate Change, Climate Change 2001: The Scientific Basis, Edited by J.T. Houghton et al., Cambridge University 
indicates that sea-level rise would have increased damages by about $1 / 4$ percent per year recently and would contribute about $1 / 2$ percent per year over the next century under the assumption of no adaptation. (Recall from an earlier section that the estimated trend in vulnerability per unit GDP was 2.9 percent per year over the last half century.) These estimates suggest that SLR will produce an upward tilt over time to the damage-intensity function.

\section{B. Adaptation}

Estimating the cost of climate change requires considering adaptations to changing conditions. "Adaptations, which can be autonomous or policy-driven, are adjustments in practices, processes, or structures to take account of changing climate conditions." 25 Adaptation to more intense hurricanes or SLR would include such factors as greater setbacks from shoreline, retreat from vulnerable areas, abandonment of damaged areas after damaging storms, and higher or improved coastal protection.

The potential role of adaptation can be seen when considering the superhigh elasticity of damages with respect to wind speed. One interpretation of the super-high elasticity discussed above is that damages occur at that point where stresses exceed the design threshold. If building codes and designs are modified in anticipation of changing hurricane intensity and SLR, then the design threshold would rise along with storm intensity. The result would be that the damageintensity function would shift out over time. This would lead to a negative time trend in the damage-intensity function shown in equation (1). Up to now, however, the time trend has been positive, indicating "negative adaptation."

Adaptation to offset SLR would involve many of the same measures as general adaptation to more intense hurricanes. A concrete example of SLR adaptation would be relocation of structures to higher or safer elevations. Using the calculations above, offsetting SLR would require upward migration of about $1 / 2$ percent per year of the capital in the most vulnerable locations. This seems a

Press, UK, 2000, Chapter 11.) We use an estimate of $5 \mathrm{~mm}$ per year over the next century to reflect the acceleration in the later part of the period.

${ }^{25}$ Contribution of Working Group II to the Third Assessment Report of the Intergovernmental Panel on Climate Change, Climate Change 2001: Impacts, Adaptation \& Vulnerability, Eds., James J. McCarthy, Osvaldo F. Canziani, Neil A. Leary, David J. Dokken and Kasey S. White, Cambridge University Press, UK, 2000, Section 1.4.1. 
manageable task for all but the most immobile capital, but again there seems no indication of such adaptation in behavior to date.

Including potential adaptation is beyond the scope of the current study. However, if changes in the means and higher moments of environmental parameters are small or gradual, and if agents make decisions on the basis of appropriate expectations, then omitting the costs of adaptation will to a first-order have no effect on correctly measured damages. The reason is due to the "envelope theorem" of decision making. ${ }^{26}$ Under this result, the first-order cost of changing environmental conditions is equal to the first-order cost of adapting to those conditions. However, if environmental conditions change very rapidly, expectations are wildly inaccurate, or the cost of adapting is very non-linear, then second-order effects come into play. We would then need to consider adaptation costs explicitly.

\section{Concluding Thoughts}

The basic story here is the following: First, there are substantial vulnerabilities to hurricanes in the southeastern coast of the United States. Damages are extremely sensitive to hurricane intensity, with the suggestion of an eighth-power law relating damages to maximum wind speed. The super-high elasticity appears to arise from threshold effects and the impact of more intense storms on capital vulnerability.

Second, greenhouse warming is likely to lead to more intense hurricanes, although the evidence on the frequency is mixed. Our simulation model calculates that the average annual hurricane damages will increase by 0.06 percent of GDP due to the intensification effect of a $\mathrm{CO}_{2}$-equivalent doubling. The empirical relationship between sea-surface temperature and frequency and intensity of storms in the North Atlantic over the last half-century suggests that this number may be significantly understated.

Third, the experience of 2005 appears to have been a quadruple outlier of nature. The number of North Atlantic storms was the highest on record; the fraction of intense storms in 2005 was above average; the fraction of the intense storms making landfall in the United States was unusually high; and one of the intense storms hit what is the most economically vulnerable region in the country.

${ }^{26}$ For a description of the invention of the envelope curve in economics, see Paul A. Samuelson, "How Foundations Came to Be," Journal of Economic Literature, Vol. 36, No. 3, September 1998, pp. 1375-1386. 
New Orleans was to the gods of natural destruction what the World Trade Towers were to the gods of human destruction.

Fourth, all this does not address the issues of whether and how the nation should rebuild New Orleans. Perhaps this analysis might relieve those who worry that the precedent of rebuilding New Orleans is a dangerous one fraught with moral hazard. People may worry that the reconstruction of New Orleans will be followed by a long string of costly post-hurricane rebuilding projects. However, the estimates in this study suggest that year after year of Katrina-sized damages is an unlikely prospect.

Finally, we should emphasize that the present economic analysis cannot capture the full social and cultural impacts of devastating hurricanes. We might note that America's first bellicose Republican President, Thomas Jefferson, threatened to go to war with France and Spain over New Orleans. He thought it the key strategic location in America, writing, "There is on the globe one single spot, the possessor of which is our natural and habitual enemy. It is New Orleans." While the city's strategic importance has doubtlessly declined over the last two centuries, Jefferson's view is a reminder that an economic reckoning cannot capture New Orleans's position as a unique quarter of American culture and history. 


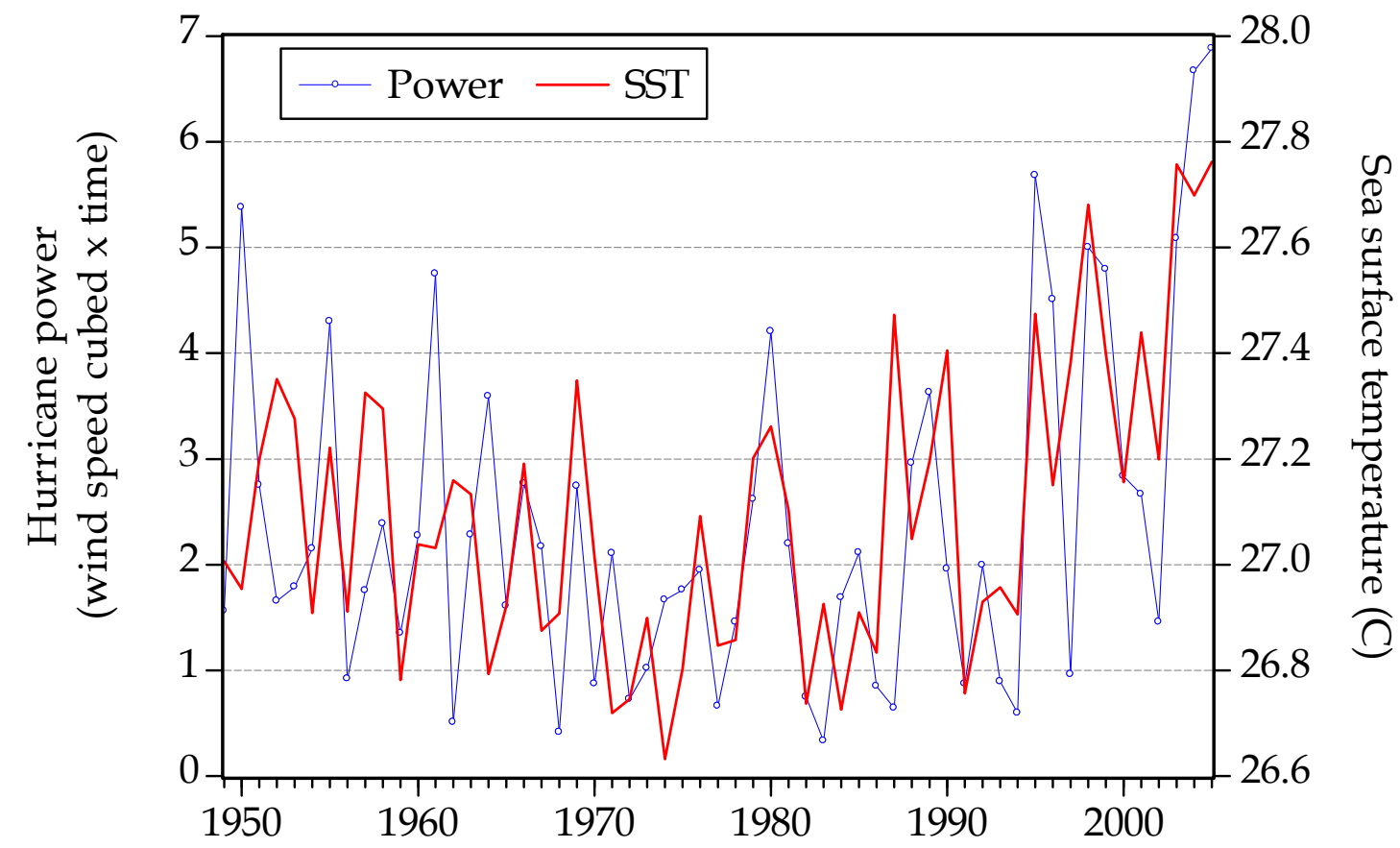

Figure 1. Index of hurricane power and sea-surface temperature 1949-2005

The hurricane power index is Emanuel's power dissipation index (PDI). Sea surface temperature is for the tropical North Atlantic.

Source: Kerry Emanuel, personal communication. Description at Kerry Emanuel, "Increasing destructiveness of tropical cyclones over the past 30 years," Nature, 436, 4 August 2005, pp. $686-688$. Note that these data are not smoothed. 


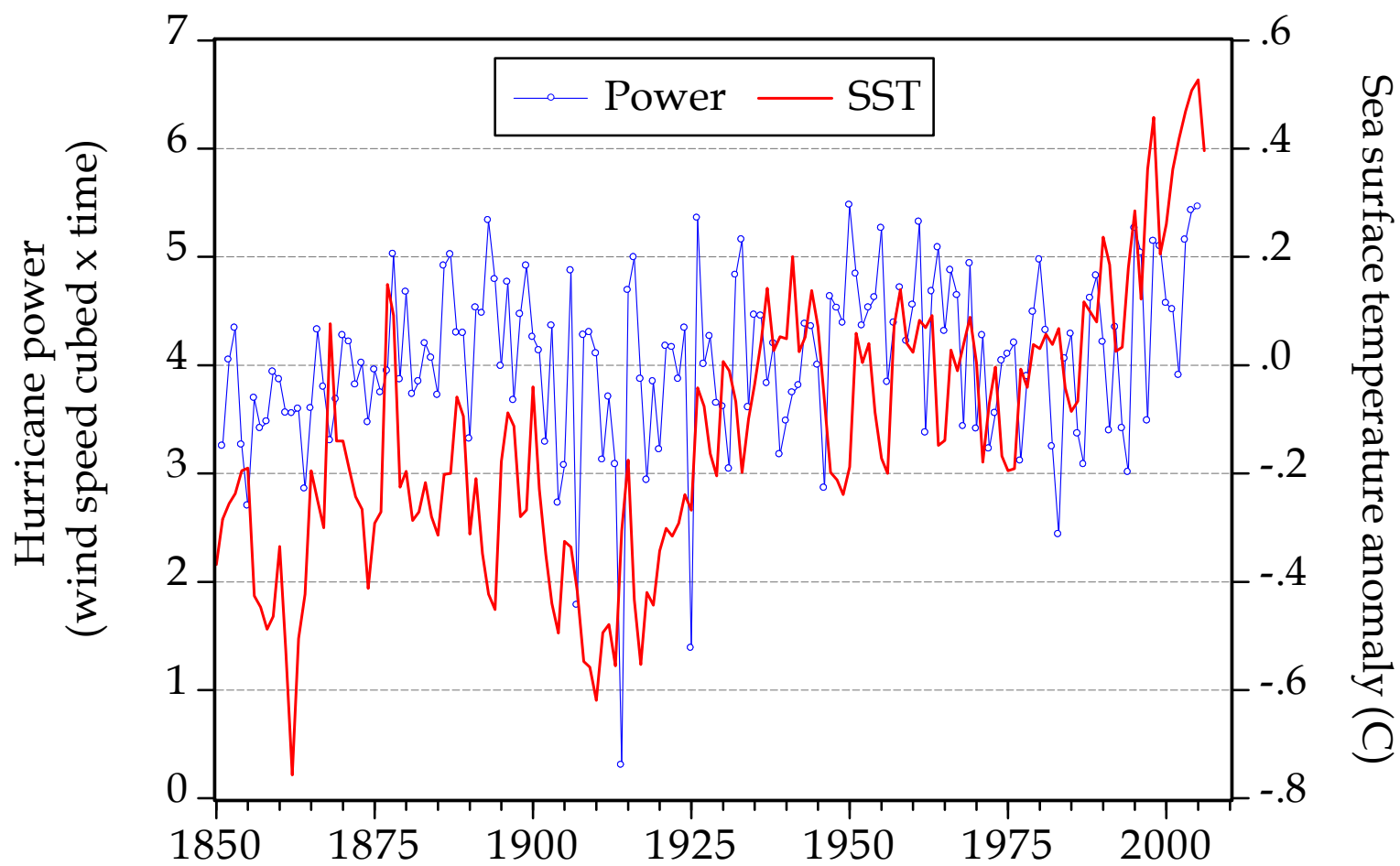

Figure 2. Hurricane Power, 1851-2005

"Hurricane power" is an index that takes the cube of the maximum sustained wind speed for each six-hour period and sums for all storms for the year. It is likely that early years underestimate power because of missing data.

Source: HURDAT data for hurricanes, and SST data from Hadley center from http://hadobs.metoffice.com/hadsst2/. 


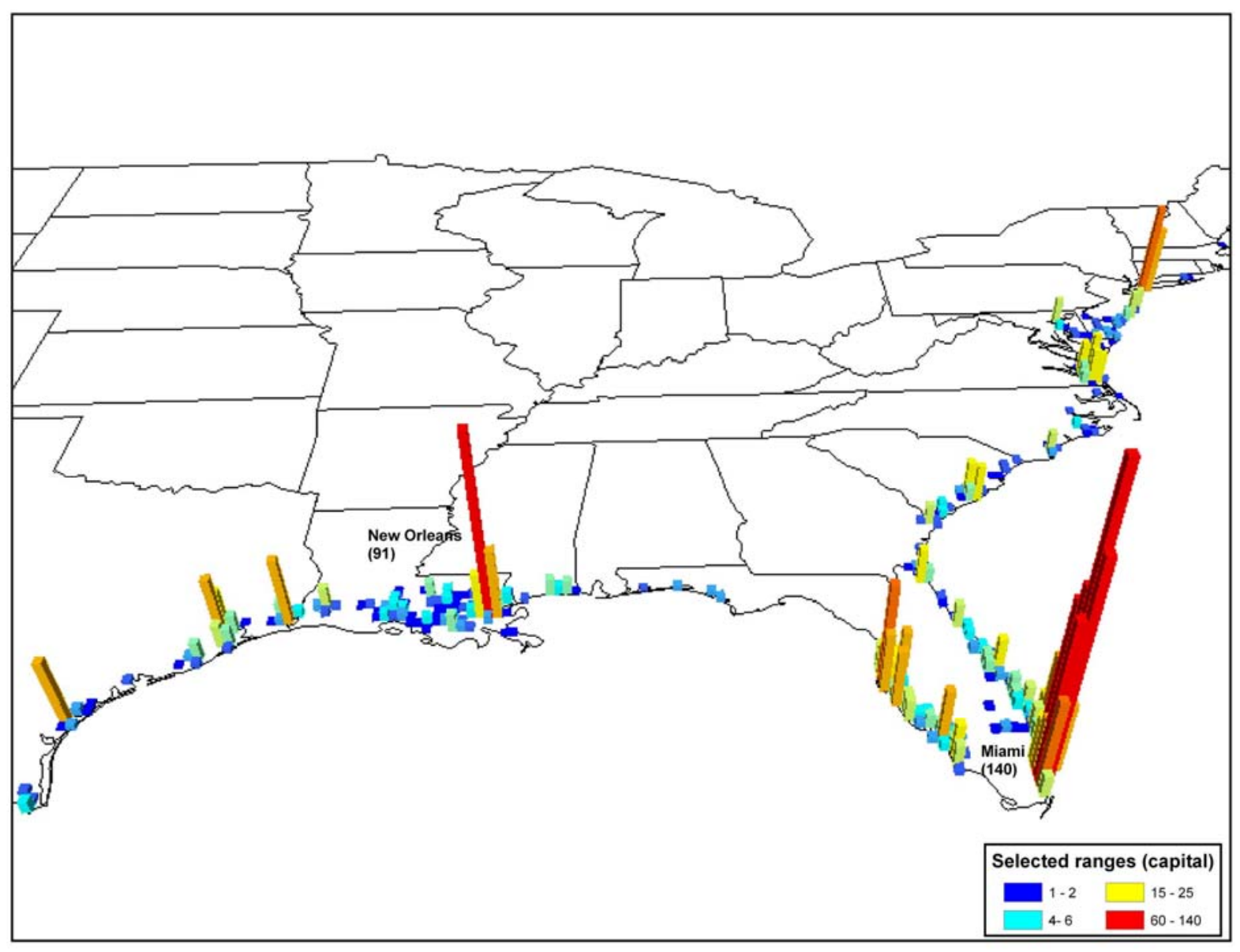

\section{Figure 3. Low-lying areas at risk of sea-level rise and storm surges}

This map shows the location of areas with mean altitude per subgridcell less than 8 meters above sea level grouped by estimated capital stock. Each subgridcell is approximately $15 \mathrm{~km} \times 15 \mathrm{~km}$. The legend shows selected colors. The numbers in parentheses are the capital stock of the largest subgridcell in the region.

Data on economic activity by grid cell are from Yale G-Econ project (see gecon.yale.edu). The data on economic activity are extrapolated to 2005 using the ratio of national capital stock in current prices in 2005 to 1990 GDP in 1995 prices. The author thanks Kyle Hood for help in preparing the subgridcell data and David Corderi for preparation of the map. 


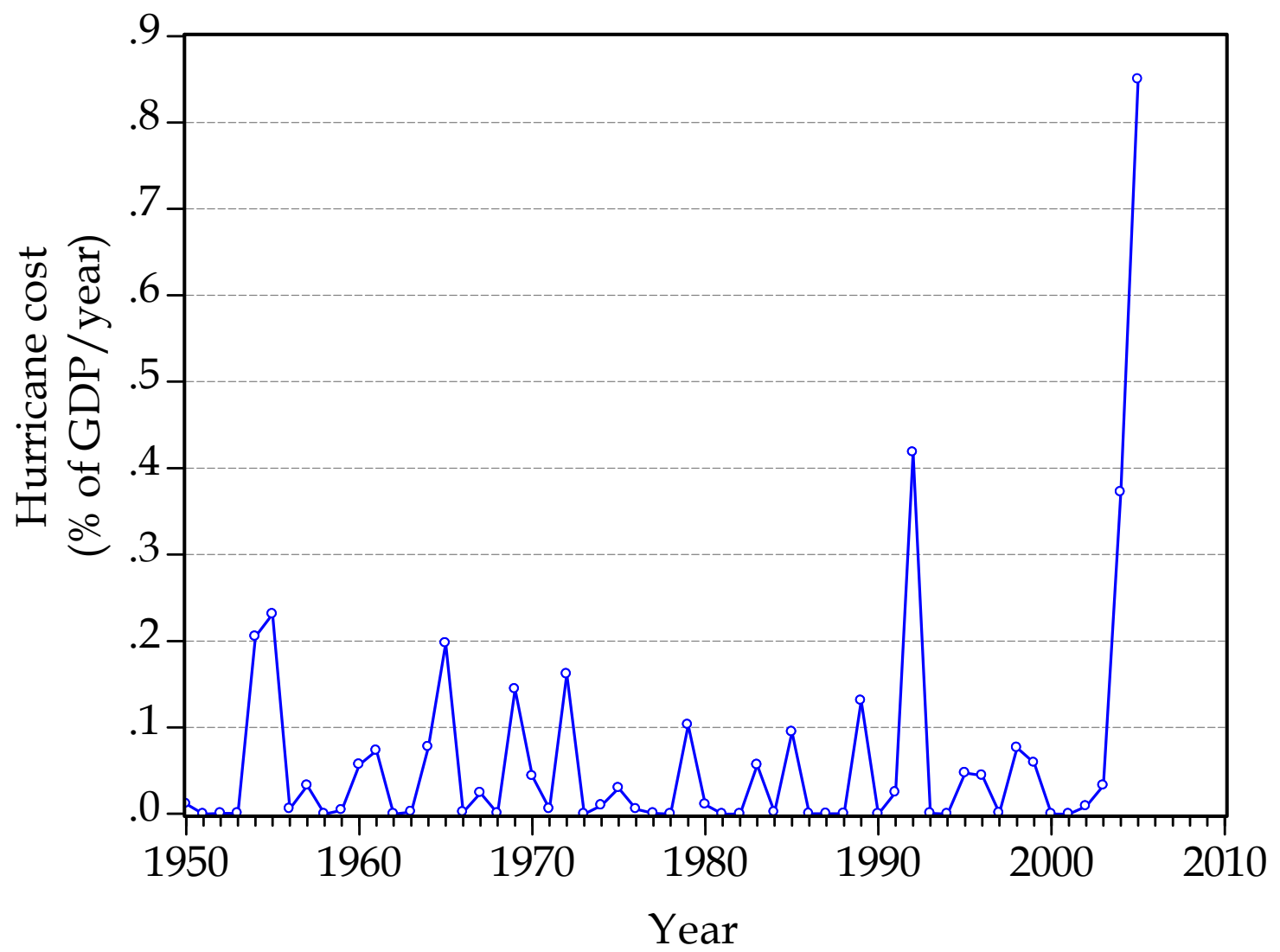

Figure 4. Normalized costs of hurricanes, 1950-2005

This figure shows the ratio of damages to GDP for all hurricanes for the given year.

Source: See text for discussion of damages. GDP from U.S. Bureau of Economic Analysis. 


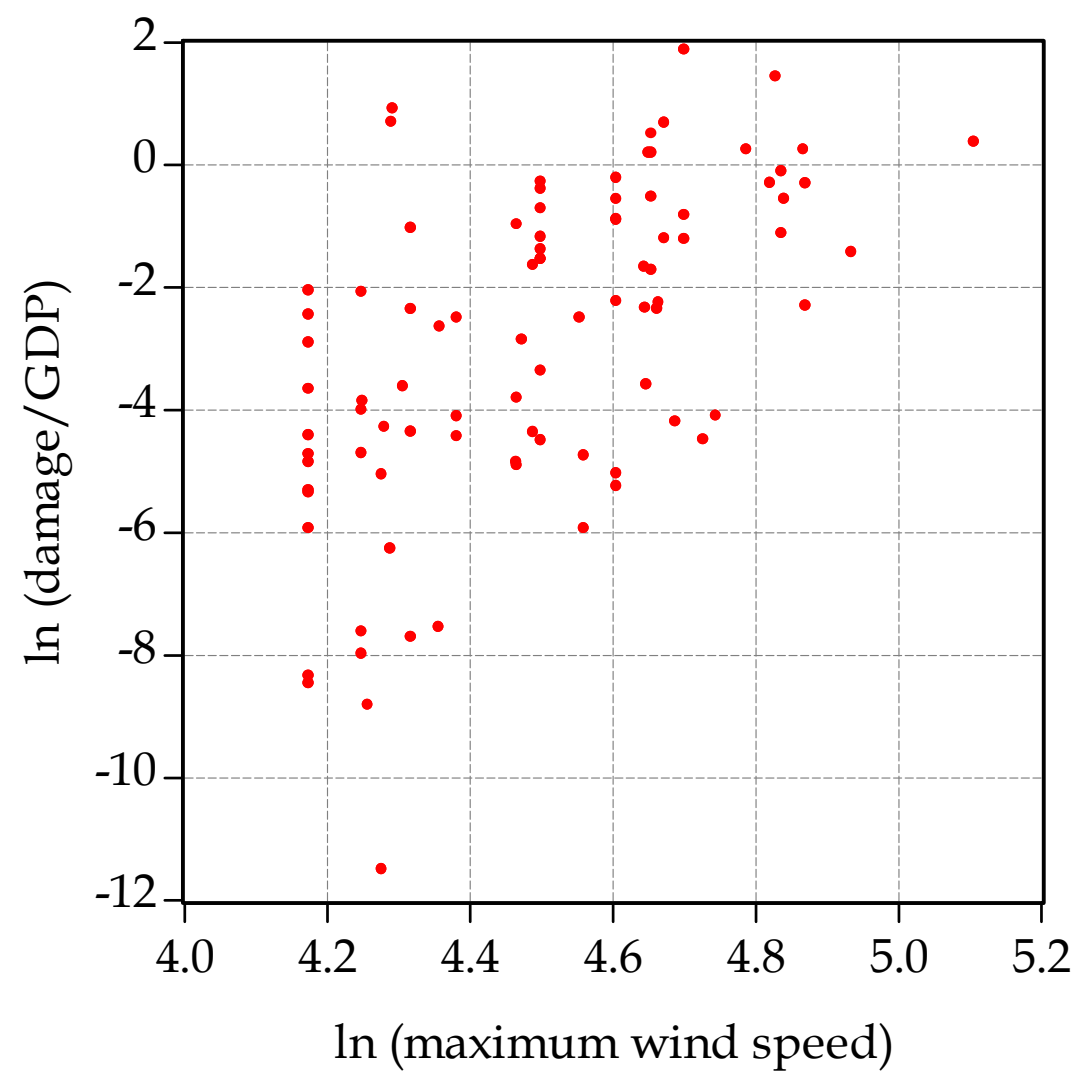

Figure 5. Wind speed and normalized damages for major hurricanes since 1950

Source: See text for definitions and data sources. 


\section{ASCE 7-98 Wind Zone Map}

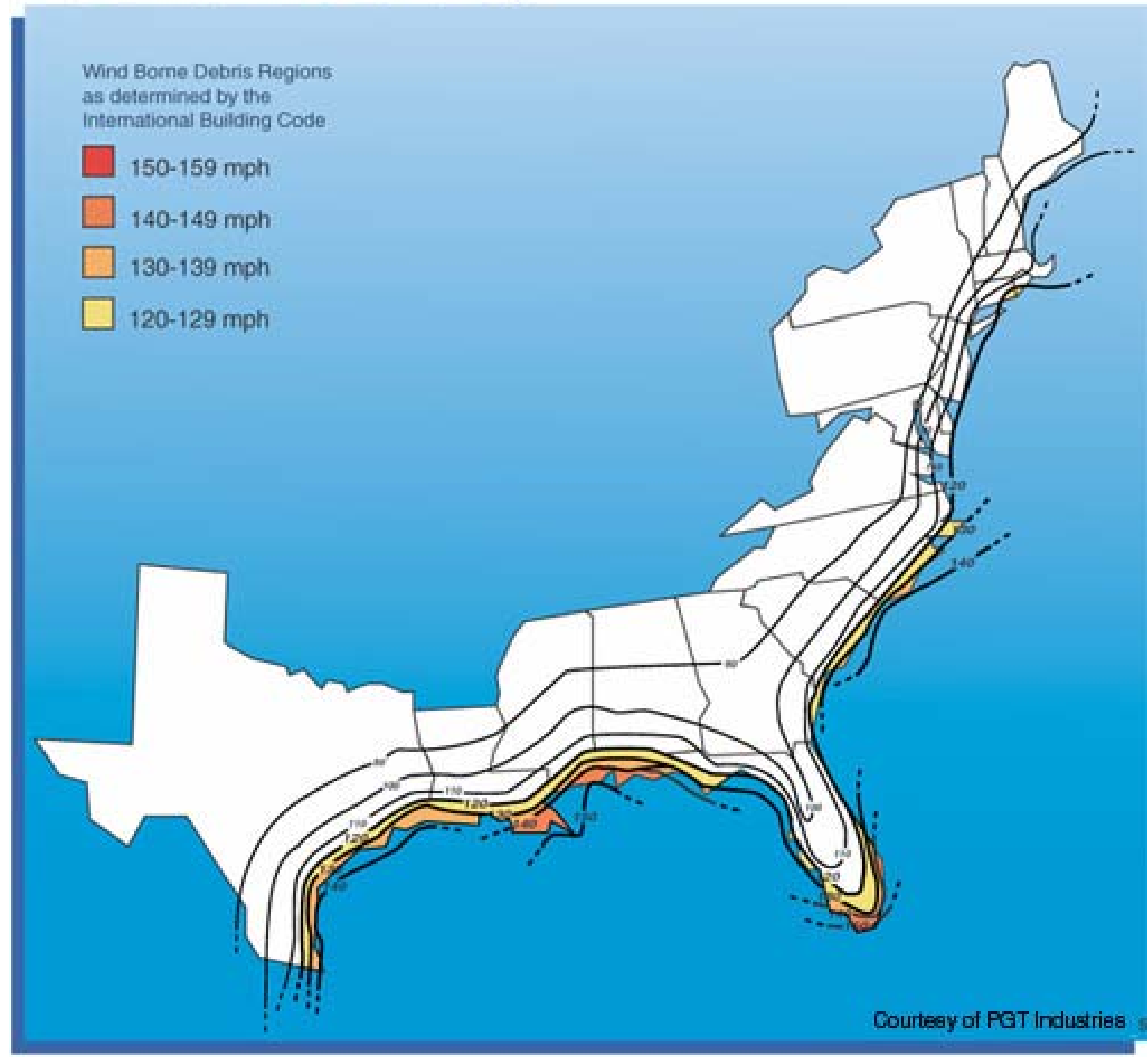

SOUACE ASCE MENMUM DESIGN LOAOS FOA BUILDINGS AND OTHEA STAUCTUAES

\section{Figure 6. Current hurricane codes for east coastal United States}

The numbers show the wind codes for minimum designs in $\mathrm{mph}$. Source:

http://www.pgtindustries.com/Products/WinGuard/FloridasNewCode.aspx 


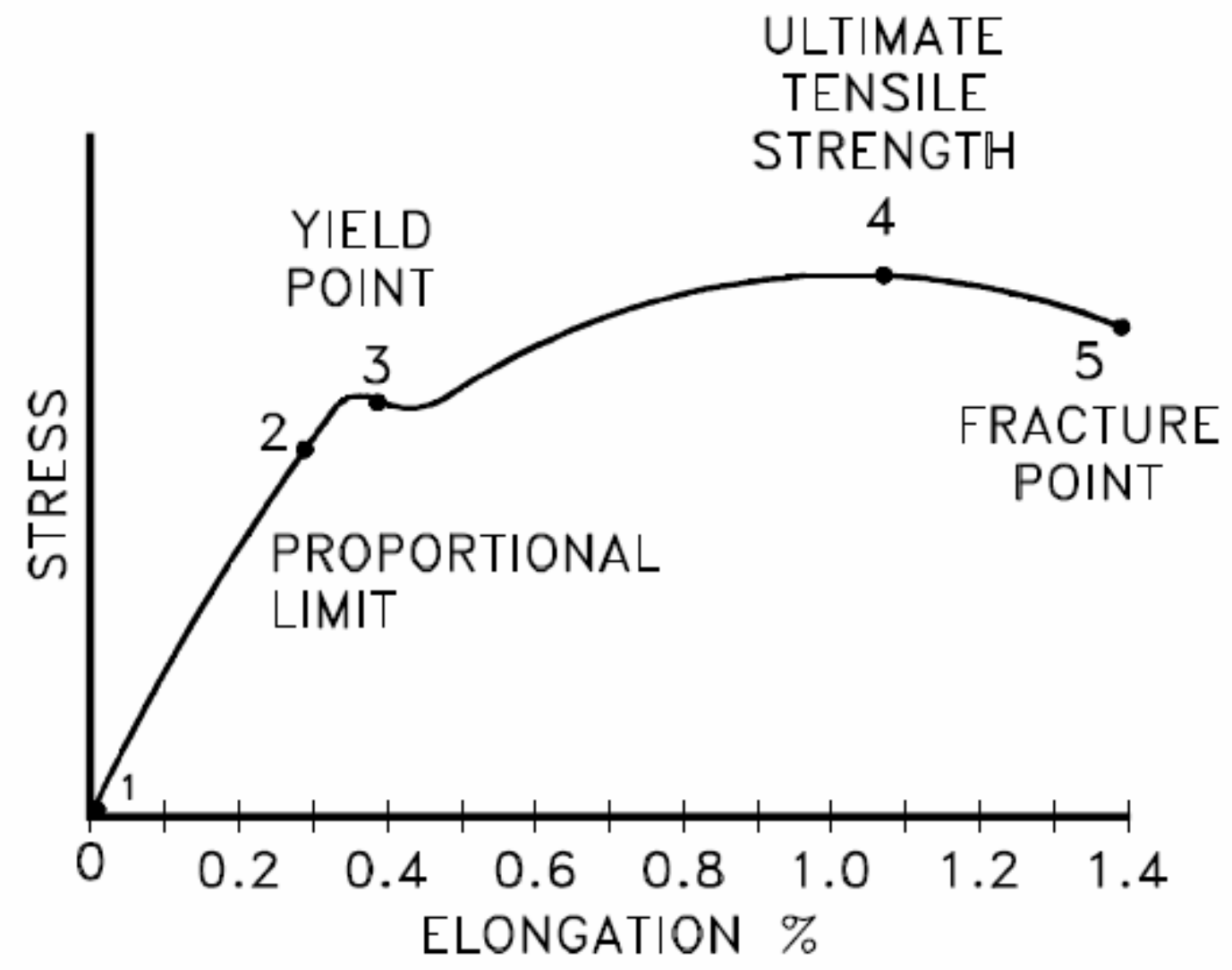

Figure 7. Stress-strain curve for a typical ductile material

Source: DOE Fundamentals Handbook: Material Science, Volume 1 of 2, U.S. Department of Energy FSC-6910, January 1993, DOE-HDBK-1017/1-93, Washington, D.C. 20585, p, "Stress-17." 


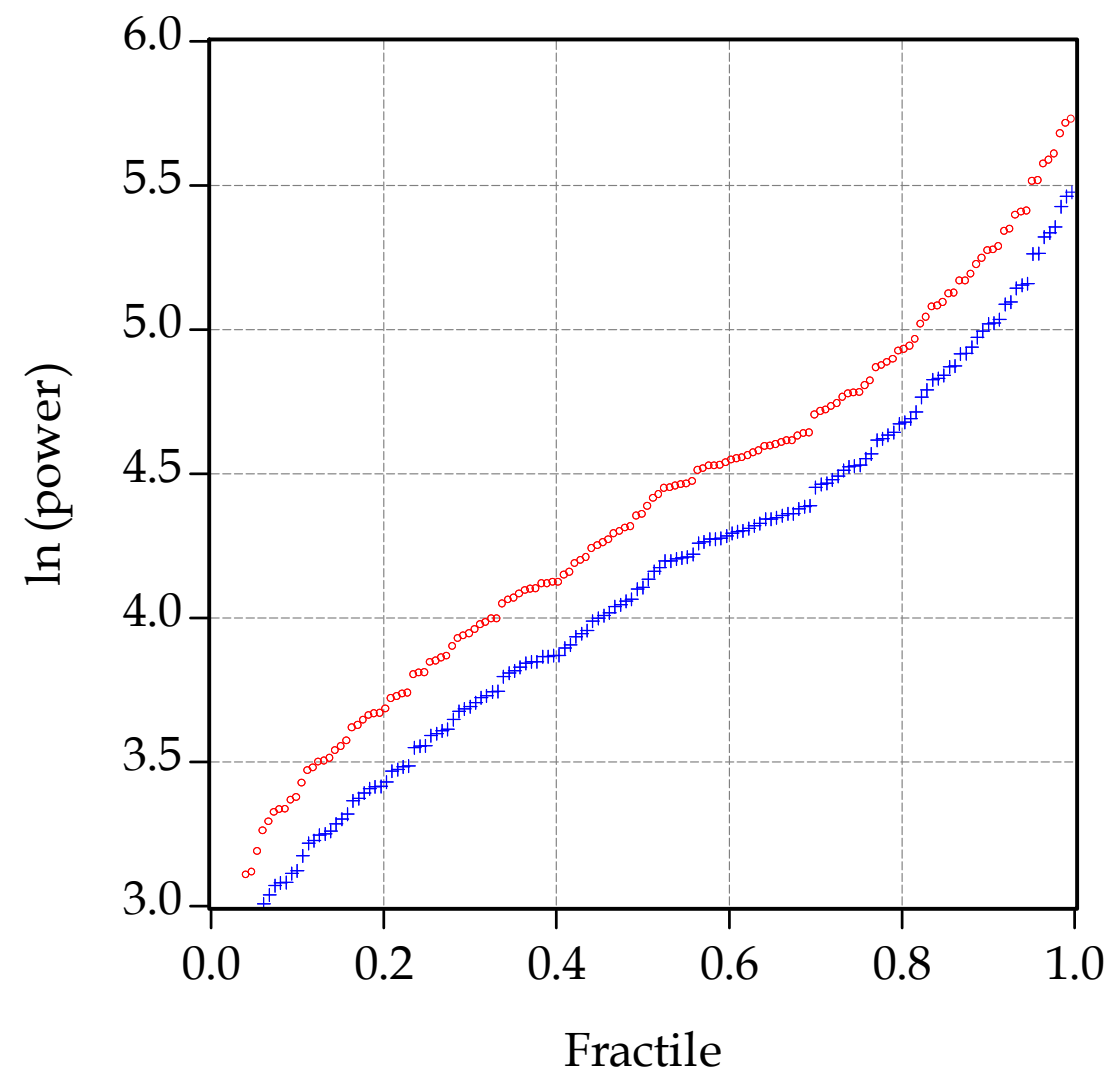

$+\ln$ (power historical) $\cdot \ln$ (power w/ warming)

Figure 8. Cumulative distribution of hurricane power: historical for 1851-2005, and estimated with global warming

Lower curve shows the cumulative distribution of annual power of hurricanes with landfall in U.S. over the 1851-2005 period. Upper red curve shows the distribution assuming no change in frequency but with the simulated increase due to global warming in equilibrium $\mathrm{CO}_{2}$ doubling scenario. Highest three points are (from the top) 1950, 2005, and 2004.

Source: Power as described in Figure 2. Global warming is central estimate as described in text. 


\begin{tabular}{|c|c|c|c|c|c|}
\hline \multirow{2}{*}{\multicolumn{2}{|c|}{$\begin{array}{r}\text { Specification } \\
\text { Period } \\
\end{array}$}} & \multicolumn{2}{|c|}{ Coefficient on $\ln$ (maxwind) } & \multicolumn{2}{|c|}{ Coefficient on year } \\
\hline & & Coefficient & t-statistic & Coefficient & t-statistic \\
\hline \multicolumn{6}{|l|}{ OLS } \\
\hline & All & 7.30 & 8.48 & 0.029 & 4.05 \\
\hline & Since 1980 & 8.45 & 5.87 & 0.076 & 2.10 \\
\hline \multicolumn{6}{|l|}{ TSLS } \\
\hline & All & 9.08 & 9.44 & 0.033 & 6.19 \\
\hline & Since 1980 & 9.73 & 6.19 & 0.072 & 1.97 \\
\hline
\end{tabular}

Table 1. Alternative Estimates of Damage-Intensity Function

This table shows four alternative estimates of equation (1). The differences are explained in the text. 


\begin{tabular}{|c|c|c|c|c|c|}
\hline Case & $\begin{array}{c}\text { (1) } \\
\text { Elasticity of } \\
\text { damages } \\
\text { w.r.t. } \\
\text { windspeed }\end{array}$ & $\begin{array}{c}\text { Semi- } \\
\text { Semicity of } \\
\text { elasticisum } \\
\text { maximum } \\
\text { wind speed } \\
\text { w.r.t. T }\end{array}$ & \begin{tabular}{|c}
$(3)$ \\
Change in \\
tropical sea- \\
surface \\
temperature \\
$(\mathrm{SST}, \mathrm{oC})$
\end{tabular} & \begin{tabular}{|c}
$(4)$ \\
Estimated \\
increase in \\
mean \\
damages \\
$(\%$ increase $)$
\end{tabular} & Source \\
\hline Central case & 8.5 & 0.035 & 2.5 & $104 \%$ & [a] \\
\hline OLS elasticity & 7.2 & 0.035 & 2.5 & $83 \%$ & [b] \\
\hline Emanuel semi-elasticity & 8.5 & 0.055 & 2.5 & $199 \%$ & [c] \\
\hline Conventional damage impact & 3.0 & 0.035 & 2.5 & $29 \%$ & [d] \\
\hline SST warming since 1950 & 8.5 & 0.035 & 0.4 & $13 \%$ & [e] \\
\hline Higher storm elasticities & 8.5 & 0.125 & 2.5 & $2018 \%$ & [f] \\
\hline
\end{tabular}

[a]: Col (1) from estimates in text relying on IV and OLS estimates; col (2) from K/T; col (3) as discussed in text.

[b]: Same as [a] except use OLS full period elasticity for col (1).

[c]: Same as [a] except use semi-elasticity in col (2) from Emanuel as discussed in text.

[d]: Same as [a] except use conventional estimate of cubic damage function.

[e]: Use estimated rise of tropical SST in Atlantic cyclogenesis region from Emanuel 2006.

[f]: Uses empirical storm elasticities. These are an elasticity of maximum wind speed

w.r.t. SST of 0.12 and a coefficient of number of hurricanes w.r.t. SST of 7.9.

\section{Table 2. Estimated mean damages from global warming: central case and alternative estimates}

This table shows the parameters underlying the estimates and the estimated increase in mean damages from equilibrium doubling of $\mathrm{CO}_{2}$ equivalent greenhouse gases. The estimate is from equation (3) in text. The best estimate is an increase of 113 percent in the first row. Other estimates range from 13 to 2018 percent with alternative parameters. The fifth row shows the estimated increase since 1950 assuming a $0.4^{\circ} \mathrm{C}$ increase in SST. 


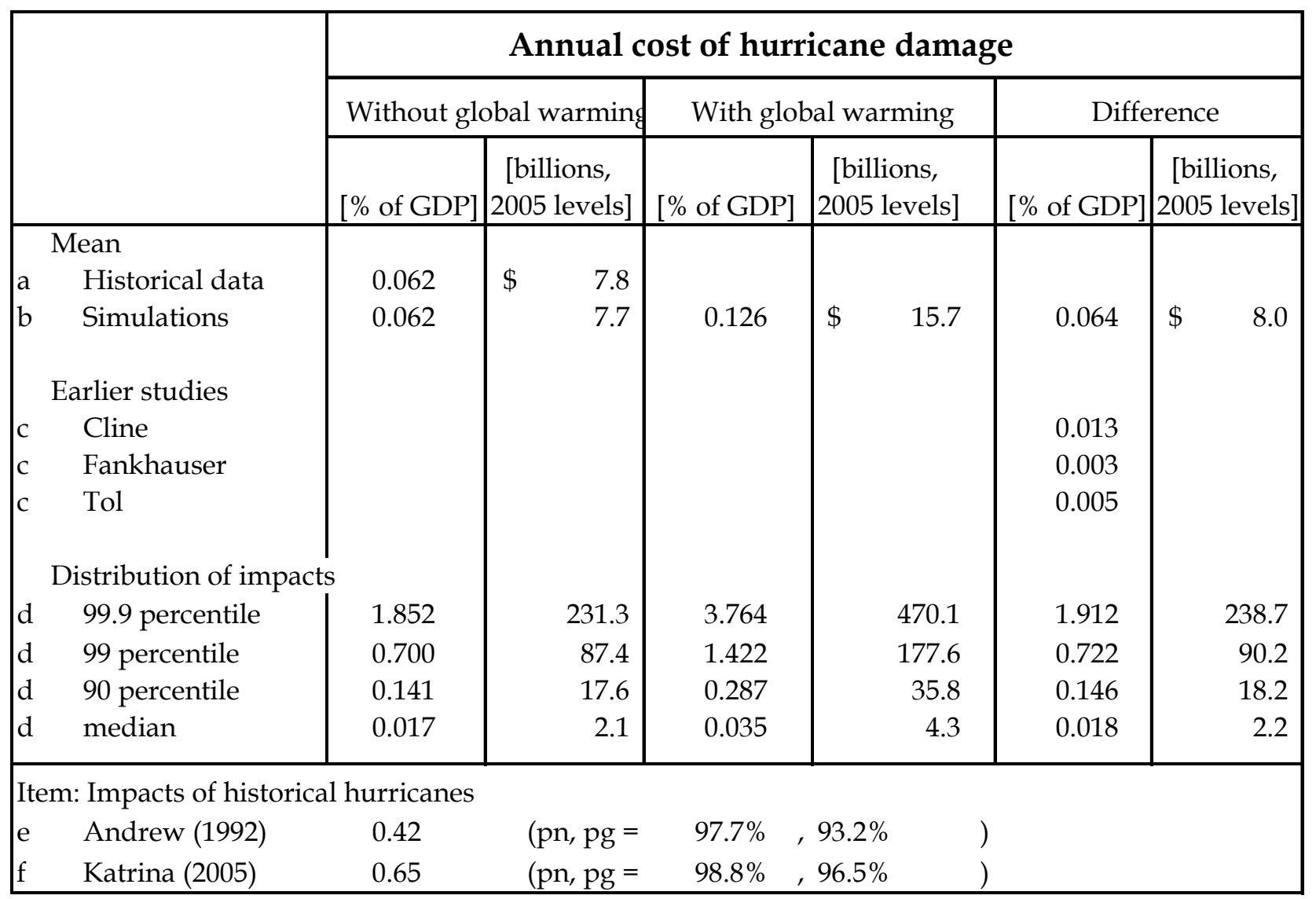

\section{Table 3. Economic Impacts of Intensification of Tropical Cyclones in the United States Due to Global Warming}

This table collates historical data as well as central estimates of the impact of global warming on the economic damages from hurricanes for the eastern U.S. (a) shows the mean impact from the historical data for 1933-2005. (b) shows estimated impacts with global warming as described in the text. (c) are estimates from earlier studies as reported in Roger A. Pielke, Jr., Roberta Klein, and Daniel Sarewitz, "Turning the Big Knob: An Evaluation of the Use of Energy Policy to Modulate Future Climate Impacts," Energy and Environment, May 2001, vol. 11, no. 3, pp. 255-275. (d) are percentiles of the distribution of years from the simulations. (e) and (f) are cost estimates as percent of GDP for two major hurricanes. The $p$ values from the simulations represent estimates of the percentile that these hurricanes lie in the distribution of impacts for both the no-global-warming and the global-warming distributions, with $\mathrm{pn}$ = percentile without global warming and $\mathrm{pg}=$ percentile with global warming. Note that these estimates do not include the effect of sea-level rise or adaptation. 


\section{Appendix. Alternative Specifications of the Damage Equation and the Capital Vulnerability Index}

The estimates of damages in equation (1) of the main text use a readily available measure of storm intensity, the maximum sustained wind speed at landfall in the United States. These estimates do not account for other characteristics of the storm or of the affected geography and economy. In principle, we would want to include some measure of the vulnerable capital in the storm's path, the lifetime of the storm, its size, as well as other geographical features such as elevation, protection by barrier islands, construction codes, and many other variables. This appendix describes extensions of the simplest storm characteristic both to determine how much is missed in the simple index and to determine whether the eighth-power law of damages can be explained by omitted variables such as other storm characteristics.

\section{A. $\underline{\text { Overview }}$}

While many other storm-related variables are difficult to measure at the scale used in this study, we have developed and estimated four alternative indexes of storm characteristics. These include:

1. The "capital vulnerability index," or CVI(N), for different powers of wind speed, $N$

2. The "terrestrial power dispersion index," or TPDI(N), for different powers of wind speed, $N$

3. The "unweighted capital vulnerability index to $100 \mathrm{~km}$," or UCVI-100

4. The "unweighted capital vulnerability index to $200 \mathrm{~km}$," or UCVI-200

I define each briefly and then provide a more detailed description. (1) The "capital vulnerability index" sums the total capital stock affected by the storm, where the capital stocks are weighted by the wind speed to the power N. (2) The "terrestrial power dispersion index" for different powers of wind speed, $N$, calculates Emanuel's power dispersion index, ${ }^{27}$ but limits the calculation to periods when the storm is near the U.S. mainland and takes wind speed to the Nth power. (3) The "unweighted capital vulnerability index to $100 \mathrm{~km}$," is similar to the CVI except that it includes all the capital stock within a $100 \mathrm{~km}$ radius of the storm center and does not weight the capital stock by wind speed. (4) The

${ }^{27}$ Kerry Emanuel, "Increasing destructiveness of tropical cyclones over the past 30 years," Nature, 436, 4 August 2005, pp. 686-688. 
"unweighted capital vulnerability index to $200 \mathrm{~km}$ " is identical to the $100 \mathrm{~km}$ variant but uses a $200 \mathrm{~km}$ radius around the storm center. For each of these measures, the measures are summed over the storm lifetime.

B. Detailed description of the capital vulnerability index (CVI)

We will describe the CVI in detail as the other measures are easily understood once the $C V I$ is explained. The basic assumption is that the quantity of vulnerable capital is proportional to the capital stock (value per subgridcell), to the time that the capital is exposed to damaging winds, and to a power function of wind speed (a polynomial function, such as cubic). The general formula for the CVI is:

$$
C V I(N)=\iiint_{u, v, t}[K(u, v)][w(u, v, t)]^{N} d u d v d t
$$

In this formula, $N$ is the exponent of the damage function, the location of the capital stock is specified by coordinates $(u, v)$, the vulnerable capital is $K(u, v)$, time is $t$, wind speed at a particular time and location is $w(u, v, t)$, and the damage function is $w(u, v, t)]^{N}$, that is, damage is proportional to wind speed to the power $N$. We do not have complete data on all the elements in equation (A1), so we use an empirical estimate of the relationship between wind speed and distance from storm center. The storm center is designated as $(u, v)=(\bar{u}, \bar{v})$. We estimate the wind velocity as $w(u, v, t)=w(\bar{u}, \bar{v})-\alpha d(u-\bar{u}, v-\bar{v})$, where $d(u-\bar{u}, v-\bar{v})$ is the Euclidian distance between the landfall point and the reference point $(u, v)$, and $\alpha$ is the parameter in the velocity decline equation. We take the discrete version of (A1) which measures the variables every six hours.

The actual calculation starts with the best-track estimates of hurricane characteristics (latitude, longitude, and maximum sustained wind speed). The calculation is performed for each U.S. subgridcell, that is, the entire Eastern U.S. divided into cells with dimensions of 10 minute by 10 minutes (roughly, $16 \mathrm{~km}$ by $10 \mathrm{~km}$ ). We then model wind speed as a cone around the hurricane center extending outwards with a decay coefficient of $\alpha=0.34 \mathrm{kts}$ per $\mathrm{km}$. This calculation gives a circle around the storm center with diminishing winds declining to zero. As an example, we show in Figure A1 the estimated wind speeds and associated subgridcell capital stocks that are calculated by the model for the time of landfall of Hurricane Andrew near Miami on August 24, 1992. 


\section{The "Terrestrial Power Dispersion Index," or TPDI $(N)$}

The terrestrial power dispersion index is similar to the CVI and is an economic variant of Emanuel's Power Dispersion Index. It differs from Emanuel's index in two ways. First, the TPDI $(N)$ is calculated only for those times when the storm is over or close to the U.S. mainland (hence terrestrial). Close is defined as $\leq$ $100 \mathrm{~km}$. Second, the PDI uses alternative exponents, $N$, whereas Emanuel's uses a power of 3 . Hence, the TPDI $(N)$ is calculated as:

$$
\operatorname{TPDI}(N)=\int_{t} \delta^{100}(\bar{u}, \bar{v}, t)[w(\bar{u}, \bar{v}, t)]^{N} d t
$$

Note that the sum is only over time because it includes only a function of maximum wind speed for the storm, $[w(\bar{u}, \bar{v}, t)]^{N}$, not at different points. $\delta^{100}(\bar{u}, \bar{v}, t)$ is a $(0,1)$ function that indicates whether the storm center is close to the U.S. mainland at time $t$ :

$$
\delta^{100}(\bar{u}, \bar{v}, t)=\left\{\begin{array}{c}
1 \text { if there is a subgridcell which contains positive } \\
\text { U.S. capital stock within a radius of } 100 \mathrm{~km} \text { of }(\bar{u}, \bar{v}, t) \\
0 \text { otherwise }
\end{array}\right.
$$

4. The "unweighted capital vulnerability index to $100 \mathrm{~km}$ " (UCVI-100) and to $200 \mathrm{~km}(U C V I-200)$

A final indexes of economic vulnerability are the "unweighted capital vulnerability index to $100 \mathrm{~km}$ " and to $200 \mathrm{~km}$. For these estimates, we calculate a "cylinder" of capital rather than the "cone" in the CVI. Because it includes all the capital stock, the wind speed is not part of the index. The index sums the values of all the capital stock within a radius of $100 \mathrm{~km}$ of the storm center for the first version, and within $200 \mathrm{~km}$ of storm center for the second version. The version for $100 \mathrm{~km}$ is as follows:

$$
U C V I-100=\iiint_{u, v, t} \phi^{100}(u, v ; \bar{u}, \bar{v}, t)[K(u, v)] d u d v d t
$$

where $\phi^{100}(u, v ; \bar{u}, \bar{v}, t)$ is a $(0,1)$ variable that indicates whether a subgridcell is within a $100 \mathrm{~km}$ radium of the storm center at time $t$ and is defined as: 


$$
\phi^{100}(u, v ; \bar{u}, \bar{v}, t)=\left\{\begin{array}{l}
1 \text { if }(u, v) \text { is a subgridcell within a radius } \\
\text { of } 100 \mathrm{~km} \text { of the storm center, }(\bar{u}, \bar{v}, t) \\
0 \text { otherwise }
\end{array}\right.
$$

The equation for UCVI-200 is completely analogous with the radius set at $200 \mathrm{~km}$ rather than $100 \mathrm{~km}$.

We can illustrate the detailed time series for some of our measures. Figure A2 shows the time series for wind speed and two measures of capital vulnerability for Hurricane Andrew in 1992. This figure shows how the CVI(3) and the UCVI-200 differ, as well as how they relate to wind speed. The model captures the high level of capital vulnerability in the Miami area in both indexes. Figure A3 shows the time series for Hurricane Katrina for CVI(9) and UCVI-200. The model correctly estimates a high level of vulnerability for the New Orleans area, although it underestimates total damages because it does not include the effects of elevation.

\section{Alternative Estimates of the Power Law for Storm Damages}

Using these new measures of storm characteristics, we can examine the determinants of storm damages. We begin with an analysis of the relationship between wind speed and hurricane damages in order to determine the extent of non-linearity of the damage function. In this analysis, we estimate the likelihood function for the exponent on wind speed in different specifications. In equation $\left(1^{\prime}\right)$, the exponent of the OLS regression of 7.3. The question investigated here is the size of the estimated exponent on wind speed in different specifications.

The results are shown in Table A1 of this Appendix. For these estimates, we limit the sample to the 89 hurricanes for which all augmented series defined in the appendix are available (essentially all landfalling hurricanes since 1950). We calculate the likelihood function for the integer values of the exponent on wind speed shown in the column labeled "Exponent (N)." For each specification, we calculate the likelihood function under the assumption that the residual errors are normally distributed and then subtract the log likelihood from the maximum value of the likelihood function for that specification. These calculations were limited to a small number of parameter values because the computer time required for calculations was approximately 2 hours per parameter value using a $3.00 \mathrm{GHz}$ Pentium 4 processor. For each case, we show the difference between the $\log$ likelihood function as a function of the exponent shown in column (a) and the maximum likelihood (ML) integer. There are five different specifications of the 
estimates, shown in columns (b) through (f), which use different measures of storm size and economic vulnerability.

Column (b) shows the log likelihood function for equation (1) in the main text where the exponent on wind speed is constrained to equal to value in column (a). That is, column (b) shows the following equation:

$$
\ln \left(\text { cost }_{i t} / G D P_{t}\right)-N \ln \left(\text { maxwind }_{i t}\right)=\alpha+\delta \text { year }_{t}+\varepsilon_{i t}
$$

where $N$ is the exponent on the maximum sustained wind. The maximum likelihood estimate is an exponent of 7 , which is the integer value of the coefficient in Table 1 of the text. The last row in column (b) shows the interpolated value from the integer estimates, which is 7.3, which is identical to the corresponding least squares regression in Table 1.

Column (c) shows estimates of the CVI(N) using different exponents, as defined in equation (A1).

$$
\left.\ln \left(\operatorname{cost}_{i t} / G D P_{t}\right)=\alpha+\beta \ln \left[C V I(N)_{i t}\right)\right]+\delta \text { year }_{t}+\varepsilon_{i t}
$$

The maximum likelihood integer value of the exponent is 4, with an interpolated maximum of 4.4. This value is considerably smaller than the estimate using wind speed alone in column (b). The reason why the ML parameter is smaller is that storm size and duration are positively correlated with maximum wind speed at landfall. Note, however, that we cannot distinguish statistically for exponents in the range of 3 to 8 .

Column (d) shows an equation in which damages are a function of the $T P D I(N)$ using different exponents in the damage function:

$$
\left.\ln \left(\operatorname{cost}_{i t} / G D P_{t}\right)=\alpha+\beta \ln \left[T P D I(N)_{i t}\right)\right]+\delta \text { year }_{t}+\varepsilon_{i t}
$$

The ML has not been reached in the parameter range with an exponent as high as 11. However, this specification cannot distinguish statistically among values between 6 and the maximum likelihood of 11. An exponent of 3 for the damage function is definitely rejected. 
Columns (e) and (f) estimate equation (1) but use a normalization of the unweighted capital vulnerability index to $100 \mathrm{~km}$ or $200 \mathrm{~km}$, the UCVI-100(N) and UCVI-200. The estimated equation for $200 \mathrm{~km}$ is:

$$
\ln \left(\operatorname{cost}_{i t} / G D P_{t}\right)-N \ln (U C V I-200)_{i t}=\alpha+\delta y_{e a r}+\varepsilon_{i t}
$$

This specification differs from the CVI index in column (c) because it assumes that vulnerable capital is uniformly distributed over the radius and that the radius is independent of storm intensity. The maximum likelihood exponents are between 8 and 9 in both cases. These are larger than the estimate for CVI because of the assumption that storm size does not increase with storm intensity.

\section{Using the Augmented Measures as Instrumental Variables}

We can also determine the potential bias in the OLS estimates by using each of the augmented measures as instruments in an IV estimate of damages. For this purpose, we estimate equation (1) in the main text using TSLS. One ambiguity arises here because each of the four augmented measures has different variants which depend upon the exponent of wind speed. We resolve this ambiguity by taking in each case the ML value of the exponent.

The results of these tests are shown in Table A2, and the different estimates are explained in the legend to the table. Using these augmented measures as instruments leads to larger estimates than the OLS estimates for the same sample. Three of the four index yield estimates of the wind speed exponent close to 8.1, while the fourth yields as estimate slightly above 10 .

\section{Choice of Specifications}

A further question is whether there is any statistical daylight among the different specifications. For this purpose, we show in Table A3 the likelihood difference between the five specifications for the common sample relative to the maximum likelihood of all estimates. The ML specification is the equation with the UCVI index (unweighted capital) with a radius of $200 \mathrm{~km}$ and an exponent of 8 (or an interpolated exponent of 8.4).

The unweighted CVI indexes in columns (e) and (f) do better than the weighted indexes; this finding probably indicates that the storm modeling assumptions are inaccurate. The simplest index used in equation (1) of the text is the least satisfactory equation for exponents in the relevant range (7 to 9). This 
result suggests that correcting for the local density of the capital stock definitely improves the quality of the damage estimates.

\section{Alternative Estimates of the Time Trend for Storm Damages}

Finally, we estimate the coefficients on year in the different specifications, shown in Table A4. For these tests, we are interested in determining whether alternative specifications change the result that damages are increasing over time (as seen by the positive coefficient on year). The estimates are robustly in the range between $2^{1 / 2}$ and $3 \frac{1}{2}$ percent per year (recall that these include landfalling hurricanes since 1950).

\section{Summary}

We can summarize these results as follows: Using an OLS specification for hurricanes since 1950, we find that for the simplest specification in equation (1) in the text, hurricane damages rise as the 7.3 power of maximum wind speed at landfall. This estimate is apparently biased downward because of errors of measurement of wind speed.

The simplest measure in equation (1) does not take into account local characteristics. If we account for the value of vulnerable capital within a fixed radius of landfall as well as the storm path and duration, this exponent rises to around $8 \frac{1}{2}$ (specifications (e) and (f) in Table A1). If we consider the entire storm history and use the TPDI, the likelihood function is too flat to distinguish exponents between 6 and 11. If we use a wind speed function that increases storm size along with intensity, as in the CVI index, the likelihood function is very flat over the entire range, with the ML exponent around $4 \frac{1}{2} 2$. In all cases, except the $C V I$, an exponent less than 7 is rejected at a 10 percent confidence level.

The major result is that the finding of a super-high elasticity of damages with respect to wind speed is found in all alternative specifications, although in some cases the statistical significance is low. 


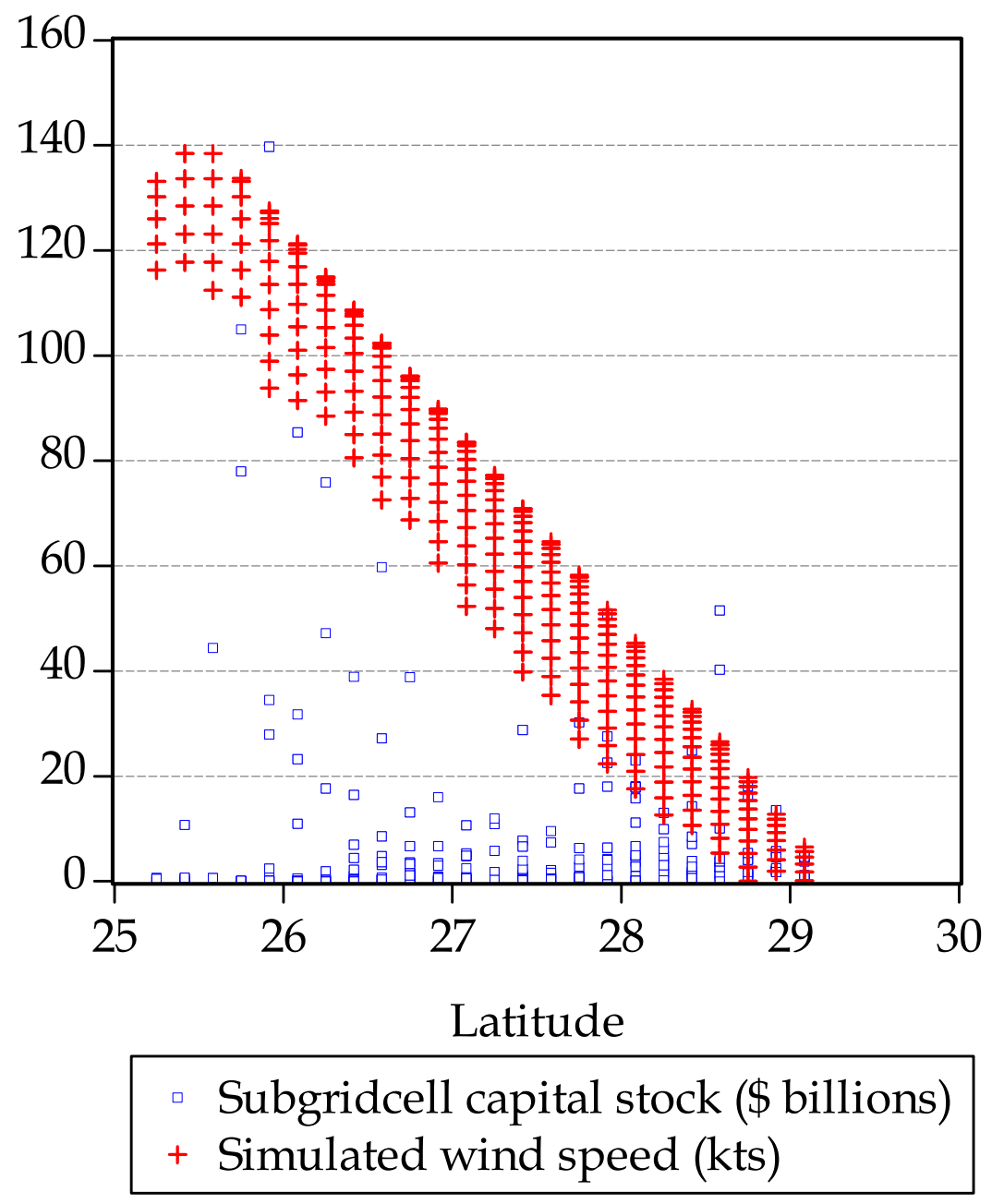

Figure A1. Simulated wind speeds and capital stock upon landfall of Hurricane Andrew

This graph shows the wind speed estimates for 9:00 UTC, August 24, 1992 for Hurricane Andrew for coastal Florida. These are sorted by latitude, and the different observations at each latitude are the longitude points in the storm area. (a) Open squares are estimated subgridcell capital stocks in billions of 2005 dollars arrayed by latitude from the G-Econ database. (b) The crosses are the estimated wind speed at that time. The center of the hurricane was estimated to be $25.5 \mathrm{~N}$ and $80.3 \mathrm{~W}$, and maximum sustained winds were estimated to be $143.3 \mathrm{kts}$. Under the model hurricane used in estimating the CVI, hurricane winds were estimated to extend $230 \mathrm{~km}$ from the center. 


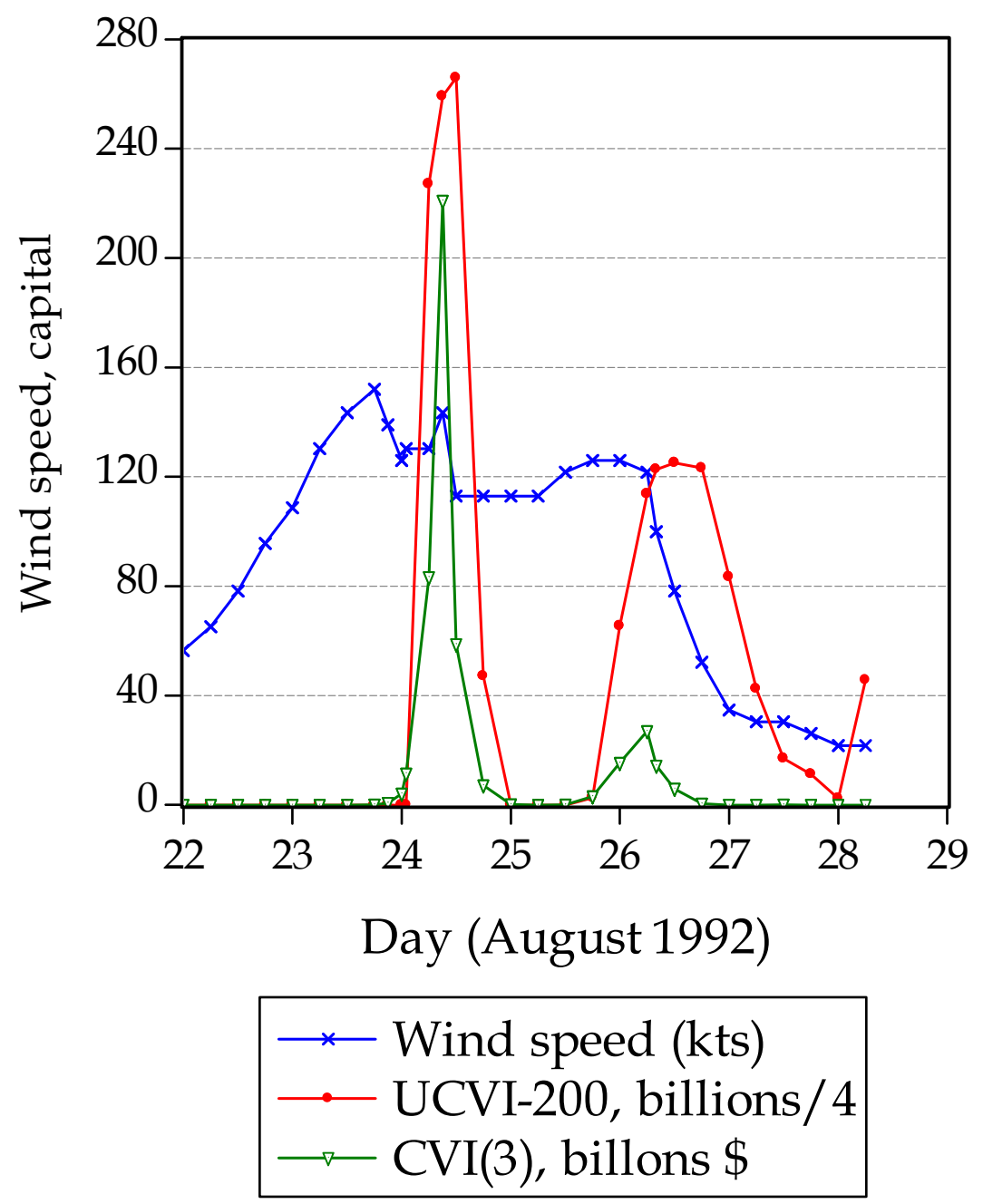

Figure A2. Wind speed and two capital vulnerability time-series estimates for Hurricane Andrew, 1992

This graph shows the time path for wind speeds and two time series for capital vulnerability measures for Hurricane Andrew in August 1992. The x shows the estimated maximum sustained wind speed at each time observation. The solid circles show the unweighted capital vulnerability index with a radium of $200 \mathrm{~km}$. The open triangles show the CVI with an exponent of 3 . Andrew had a double landfall, with the earlier one experiencing a higher wind speed and a more capital-intensive location (Miami), while the second landfall over Louisiana had lower winds in a less densely populated zone, after which the storm rapidly died. 


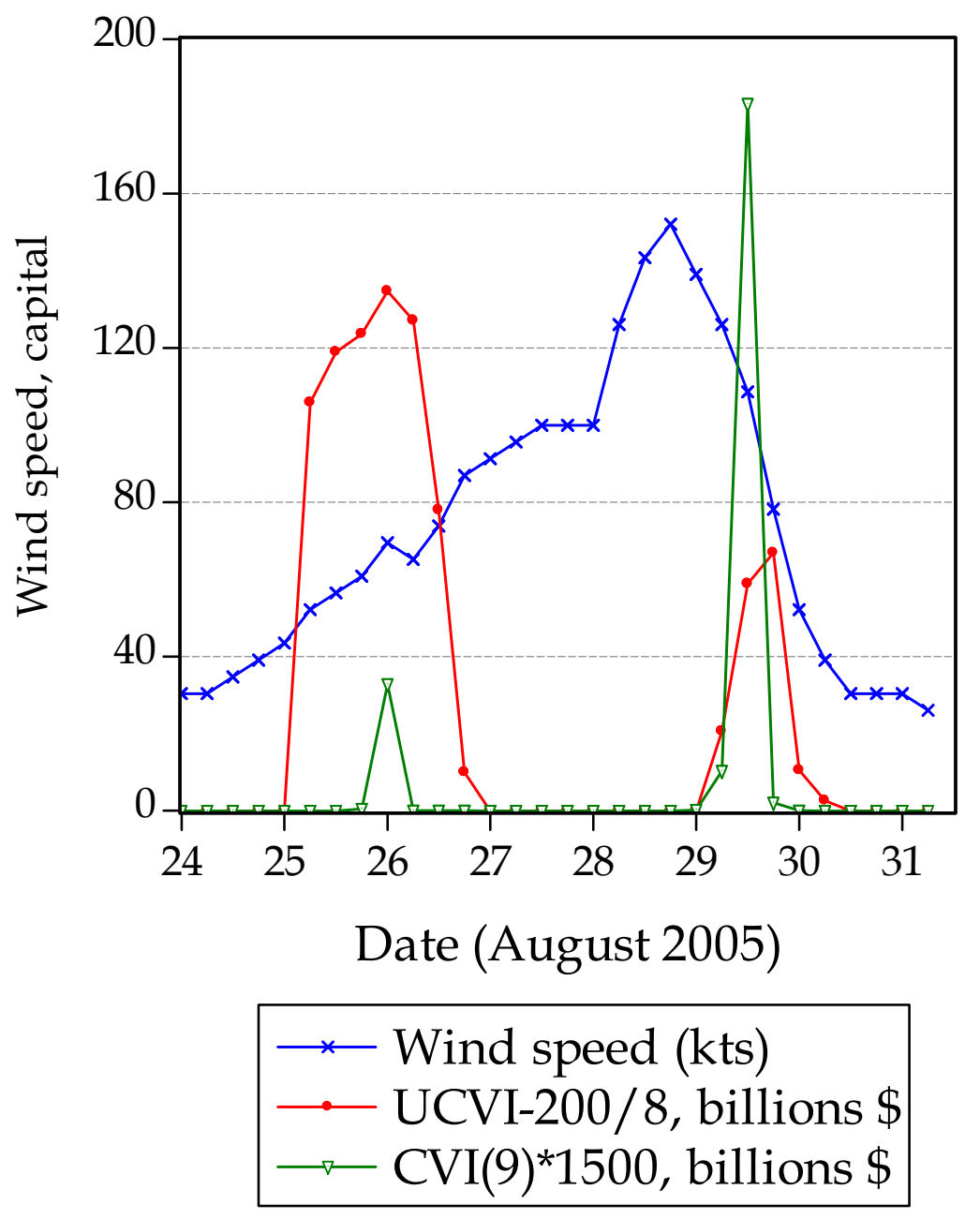

Figure A3. Wind speed and two capital vulnerability time-series estimates for Hurricane Katrina, 2005

This graph shows the time path for wind speeds and two time series for capital vulnerability measures for Hurricane Katrina in August 2005. The legend is the same as in Figure A2. This index uses CVI(9), whereas Figure A3 uses CVI(3). Katrina was a double hit. Even though the wind speeds were comparable in the two hits, the vulnerable capital with the eighth power law was much greater for the hit in New Orleans on August 29 than the Florida hit on August 25. 


\begin{tabular}{|c|c|c|c|c|c|}
\hline (a) & (b) & (c) & (d) & (e) & (f) \\
\hline Exponent $(\mathrm{N})$ & $\begin{array}{l}\text { Difference ln } \\
\text { likelihood, } \\
\text { maxwind(N) }\end{array}$ & $\begin{array}{c}\text { Difference ln } \\
\text { likelihood, } \\
\text { CVI(N) }\end{array}$ & $\begin{array}{c}\text { Difference ln } \\
\text { likelihood, } \\
\text { PDI(N) }\end{array}$ & $\begin{array}{c}\text { Difference } \ln \\
\text { likelihood, } \\
\text { distance }< \\
100 \mathrm{~km}\end{array}$ & $\begin{array}{c}\text { Difference ln } \\
\text { likelihood, } \\
\text { distance < } \\
200 \mathrm{~km}\end{array}$ \\
\hline 1 & -16.3 & & -19.9 & -23.1 & -23.1 \\
\hline 2 & -12.1 & & -13.2 & -18.5 & -18.3 \\
\hline 3 & -8.2 & -0.5 & -7.3 & -14.0 & -13.7 \\
\hline 4 & -5.0 & 0.0 & -4.1 & -9.9 & -9.5 \\
\hline 5 & -2.4 & -0.1 & -2.4 & -6.3 & -5.9 \\
\hline 6 & -0.7 & -0.4 & -1.5 & -3.4 & -3.0 \\
\hline 7 & 0.0 & -0.9 & -0.9 & -1.3 & -1.0 \\
\hline 8 & -0.3 & -1.4 & -0.5 & -0.1 & 0.0 \\
\hline 9 & -1.5 & -1.8 & -0.3 & 0.0 & -0.1 \\
\hline 10 & -3.7 & & -0.1 & -0.9 & -1.3 \\
\hline 11 & -6.7 & & 0.0 & -2.8 & -3.5 \\
\hline 12 & -10.3 & & & -5.6 & -6.6 \\
\hline $\begin{array}{c}\text { Interpolated } \\
\text { ML }\end{array}$ & 7.3 & 4.4 & $11+$ & 8.6 & 8.4 \\
\hline
\end{tabular}

\section{Table A1. Likelihood function for exponent on wind speed under different specifications}

Table A1 shows the log likelihood difference between regressions with the given exponent and the maximum likelihood (ML) integer exponent for five different specifications of the damage equation. The bold face number is the maximum likelihood integer exponent. Log likelihood differences in shaded region are ones that are not significantly different from the maximum likelihood estimate at the 10 percent significance level. The number at bottom is the estimated maximum likelihood value using a quadratic fit to likelihood function.

Specifications are the following: (a) is exponent on wind speed. (b) is equation (1) with alternative exponents of wind speed; (c) is CVI $(N)$; (d) is estimate of the TPDI(N) for observations within $100 \mathrm{~km}$ of U.S. terrestrial grid cell; (e) is equation (1) where damage is normalized by capital stock within $100 \mathrm{~km}$ of storm center; (f) is equation (1) where damage is normalized by capital stock within $200 \mathrm{~km}$ of storm center. 


\begin{tabular}{|l|l|l|l|c|c|}
\hline $\begin{array}{l}\text { Equation } \\
\text { Number }\end{array}$ & Estimate & Instrument & $\begin{array}{l}\text { Sample } \\
\text { period }\end{array}$ & $\begin{array}{c}\text { Exponent on } \\
\text { wind speed }\end{array}$ & $\begin{array}{c}\text { Standard error } \\
\text { of coefficient }\end{array}$ \\
\hline i & OLS & None & Total sample & 7.30 & 0.86 \\
ii & TSLS & MB and SSScale & Total sample & 9.08 & 0.96 \\
iii & OLS & None & Sample with CVI & 7.23 & 1.01 \\
iv & TSLS & MB and SSScale & Sample with CVI & 8.84 & 1.12 \\
v & TSLS & PDI & Sample with CVI & 8.21 & \\
vi & TSLS & CVI & Sample with CVI & 10.09 & \\
vii & TSLS & UCVI-100 & Sample with CVI & 8.00 & \\
viii & TSLS & UCVI-200 & Sample with CVI & 8.10 & \\
\hline
\end{tabular}

\section{Table A2. Alternative Instrumental Variable Estimates for Exponent on Maximum Wind Speed in Equation (1)}

This table shows different estimates of the exponent in equation (1). Equation (i) is the initial estimate for the entire sample, while equation (ii) is the TSLS estimate of the same equation. These estimates are also reported in Table 1 of the text. Equations (iii) and (iv) report the same estimators but limit the sample to the period in which we estimate the broader CVI and other indexes. There is very little change from limiting to the CVI sample. Equations (v) through (viii) report the estimates where the broader indexes are used as instrumental variables. Three of the four are slightly above 8 , while the CVI is more than 10. 


\begin{tabular}{|c|c|c|c|c|c|}
\hline $\begin{array}{c}\text { Exponent } \\
(\mathrm{N})\end{array}$ & \begin{tabular}{|c} 
(b) \\
Difference ln \\
likelihood, \\
maxwind(N)
\end{tabular} & $\begin{array}{c}\text { (c) } \\
\text { Difference } \\
\ln \\
\text { likelihood, } \\
\text { CVI(N) }\end{array}$ & $\begin{array}{c}(\mathrm{d}) \\
\text { Difference } \\
\ln \\
\text { likelihood, } \\
\text { PDI(N) }\end{array}$ & $\begin{array}{c}(\mathrm{e}) \\
\text { Difference ln } \\
\text { likelihood, } \\
\text { distance < } \\
100 \mathrm{~km}\end{array}$ & $\begin{array}{c}(\mathrm{f}) \\
\text { Differenc } \\
\text { e ln } \\
\text { likelihood } \\
\text {, distance } \\
<200 \mathrm{~km}\end{array}$ \\
\hline 1 & $-20.1 * * *$ & & & $-25.5 * * *$ & $-23.1 * * *$ \\
\hline 2 & $-15.9 * * *$ & & & $-20.9 * * *$ & $-18.3 * * *$ \\
\hline 3 & $-12.0 * * *$ & -2.6 & $-9.6 * * *$ & $-16.4 * * *$ & $-13.7 * * *$ \\
\hline 4 & $-8.8 * * *$ & -2.1 & $-6.4 * *$ & $-12.3 * * *$ & $-9.5 * * *$ \\
\hline 5 & $-6.2 * *$ & -2.2 & $-4.7 * *$ & $-8.7 * * *$ & $-5.9 * *$ \\
\hline 6 & -4.5 ** & -2.5 & $-3.8 *$ & -5.8 ** & $-3.0 *$ \\
\hline 7 & $-3.8 *$ & $-3.0 *$ & $-3.2 *$ & $-3.7 *$ & -1.0 \\
\hline 8 & $-4.1 * *$ & -3.4 * & $-2.9 *$ & -2.5 & 0.0 \\
\hline 9 & -5.4 ** & $-3.9 * *$ & -2.6 & -2.4 & -0.1 \\
\hline 10 & $-7.5 * * *$ & & & $-3.3 *$ & -1.3 \\
\hline 11 & $-10.5 * * *$ & & & $-5.2 * *$ & $-3.5 *$ \\
\hline 12 & $-14.1 * * *$ & & & $-8.0^{* * * *}$ & -6.6 ** \\
\hline
\end{tabular}

\section{Table A3. Likelihood difference over exponents and specifications}

The table shows the difference in log likelihood between the given specification and the maximum likelihood (ML) specification. The asterisks represent the same significance for the likelihood-ratio test, where the tests are for nested equations using a chi-squared distribution with 1 degree of freedom. Those equations which are insignificantly different from the ML specification are in bold and in the shaded regions. The asterisks next to the coefficients are keyed as follows: ${ }^{*}=$ significantly different from the ML equation at the 10 percent level; ${ }^{* *}=$ significant at the 5 percent level; and ${ }^{* *}$ is significant at the 1 percent level. 


\begin{tabular}{|c|c|c|c|c|c|}
\hline $\begin{array}{l}\text { Exponent } \\
(\mathrm{N})\end{array}$ & $\begin{array}{c}(\mathrm{b}) \\
\text { Base equation } \\
\text { with } \\
\text { maximum } \\
\text { wind at } \\
\text { landfall to } \\
\text { exponent }(\mathrm{N})\end{array}$ & $\begin{array}{c}\text { Equation with } \\
\text { CVI }\end{array}$ & $\begin{array}{c}\text { Equation with } \\
\text { PDI }\end{array}$ & $\begin{array}{c}\text { Equation with } \\
\text { distance }<100 \\
\text { km }\end{array}$ & $\begin{array}{c}\text { Equation with } \\
\text { distance }<200 \\
\mathrm{~km}\end{array}$ \\
\hline 1 & $0.017^{* *}$ & & & 0.027 * & 0.024 \\
\hline 2 & 0.019 ** & & & 0.028 * & 0.026 * \\
\hline 3 & $0.021 * * *$ & 0.025 * & 0.025 * & $0.030 *$ & 0.027 * \\
\hline 4 & $0.023 * * *$ & 0.024 * & 0.024 * & 0.032 ** & 0.029 * \\
\hline 5 & $0.025 * * *$ & 0.024 * & 0.023 * & $0.033 * *$ & $0.030 * *$ \\
\hline 6 & $0.027 * * *$ & 0.023 * & 0.023 * & 0.035 ** & 0.032 ** \\
\hline 7 & $0.029 * * *$ & 0.023 * & 0.022 * & 0.036 ** & 0.034 ** \\
\hline 8 & $0.031 * * *$ & 0.023 * & 0.022 * & 0.038 ** & $0.035 * *$ \\
\hline 9 & $0.033 * * *$ & 0.022 * & 0.022 * & $0.039 * *$ & $0.037 * *$ \\
\hline 10 & 0.034 *** & & & $0.041 * *$ & $0.038 * *$ \\
\hline 11 & $0.036 * * *$ & & & $0.042 * * *$ & $0.040 * * *$ \\
\hline 12 & $0.038 * * *$ & & & $0.044 * * *$ & $0.041^{* * *}$ \\
\hline
\end{tabular}

\section{Table A4. Coefficients on year in alternative regressions}

This table collates the coefficient on the time trend for different specifications. The specifications are identical to those in Tables A1 and A2.

In each column, we show the coefficient on year as a function of the exponent in the first column and for that specification. The bold number is the ML estimate for that specification, while the shaded entries are ones that are not significantly different from the ML estimates. The asterisks next to the coefficients are keyed as follows: ${ }^{*}=$ significantly different from zero at the two-tail 10 percent level; ${ }^{* *}=$ significant at the two-tail 5 percent level; and ${ }^{* * *}$ is significant at the two-tail 1 percent level. 